\author{
Research article \\ urn:1sid:zoobank.org:pub:0F0273D4-7839-4760-B656-5CDC92977BCD
}

\title{
Laophontodes typicus T. Scott (Copepoda, Harpacticoida, Laophontodinae) - discovering a species complex by morphology
}

\author{
Kai Horst GEORGE \\ Senckenberg am Meer, Abt. Deutsches Zentrum für Marine Biodiversitätsforschung DZMB, \\ Südstrand 44, D-26382 Wilhelmshaven, Germany. \\ Email:kgeorge@senckenberg.de
}

urn:1sid:zoobank.org:author:4399979D-C00B-4798-A524-2F51E8DAB73C

\begin{abstract}
It appeared necessary to undertake a redescription of Laophontodes typicus T. Scott, 1894, but with the absence of the type specimen, several additional individuals collected from a number of regions were studied. The specimens chosen were from the western coast of Sussex and the Scottish Firth of Forth (UK), the Skjerstad fjord (Norway), the Patagonian continental slope (Chile) and the Great Meteor Seamount (subtropical north-eastern Atlantic Ocean). All specimens examined had been previously determined as L. typicus and deposited in the collections of renowned research institutions. However, detailed morphological comparison revealed that only the Sussex material can be assigned to L. typicus; the remaining specimens represent distinct species whose original assignment to L. typicus was erroneous, due to a morphological ambiguity. Thus, the current status of L. typicus must be regarded as a species complex. The Sussex material enabled a detailed redescription of L. typicus. Additionally, five new species are described, namely $L$. scottorum sp. nov., L. sarsi sp. nov., L. gertraudae sp. nov., $L$. monsmaris sp. nov. and $L$. norvegicus sp. nov. They exhibit some morphological similarity, but equally present discrete characters justifying their establishment as distinct taxa. The descriptions are accompanied by a detailed discussion that explains the justification of the splitting of L. typicus.
\end{abstract}

Keywords. Crustacea, meiofauna, Ancorabolidae, systematics, taxonomy.

George K.H. 2018. Laophontodes typicus T. Scott (Copepoda, Harpacticoida, Laophontodinae) - discovering a species complex by morphology. European Journal of Taxonomy 439: 1-43. https://doi.org/10.5852/ejt.2018.439

\section{Introduction}

To elucidate the phylogenetic relationships within Laophontodinae Lang, 1944 (Copepoda, Harpacticoida), several studies have focused on specific laophontodin taxa (Conroy-Dalton 2004; George 2006, 2017; Gheerardyn \& Lee 2012; George \& Gheerardyn 2015). These studies have improved our knowledge of the systematic relationships of and within that taxon and even within the genera examined. As a result, the type genus Laophontodes T. Scott, 1894 was split into several genera (Calypsophontodes Gheerardyn \& Lee, 2012; Lobopleura Conroy-Dalton, 2004; Paralaophontodes Lang, 1965) and a number of species have been redescribed. This has contributed remarkably to a clarification of the systematics within the genus Laophontodes (Lang 1965; Conroy-Dalton 2004; Gheerardyn \& Lee 2012; George \& Gheerardyn 2015; George 2017). 
The work so far undertaken is leading towards an increasingly unambiguous phylogenetic characterization of a monophylum Laophontodes. In that context, a re-examination and redescription of the type species Laophontodes typicus T. Scott, 1894 appeared to be a useful further step. Since its description from the Scottish coast (T. Scott 1894), L. typicus has been reported over a wide geographical area (e.g., T. Scott 1903, 1907; Sars 1908; Jakubisiak 1933, 1936; Lang 1948; Klie 1950; Roe 1958; Chislenko 1967, 1977; George 1999, 2005; George \& Schminke 2002; Kornev \& Chertoprud 2008; Ventham 2011) and some of these reports included at least partial redescriptions (T. Scott 1907; Sars 1908; Klie 1950 (only textual); Chislenko 1967, 1977), as is the intention of the present contribution. Unfortunately, the type material of L. typicus is unavailable (Lowe, pers. comm.), so material collected in Scotland (UK) and determined by Thomas Scott was compared with material sampled by Georg O. Sars, along with material found at the Great Meteor Seamount (George \& Schminke 2002), the Chilean Magellan Region (George 1999, 2005) and the Sussex coast, southern England (Ventham 2011). The aim was to incorporate earlier redescriptions in a detailed and updated redescription of Laophontodes typicus that included all recognized morphological variability. However, careful comparison of the redescriptions revealed several morphological inconsistencies neglected to date.

The inconsistencies found between the redescription and the original description include the presence/ absence of an antennary exp, the presence/absence of a minute seta with the maxillipedal claw and the presence/absence of a minute seta on P1 enp-2. Determining whether these differences document an intraspecific variability or point towards the existence of cryptic species is hindered by the possibility/ probability that some morphological characters have been overlooked by individual authors. This is further complicated by the absence of most of the described material, precluding a re-examination. Nevertheless, it became clear that the specimens previously assigned to L. typicus, actually belong to different morphospecies, and, therefore, that $L$. typicus represents a species complex requiring a significant revision.

\section{Material and methods}

For the taxonomic comparison and redescription of species the following material, from five geographical locations, was studied (Fig. 1): Laophontodes typicus T. Scott, 1894 from the Sussex coast (eastern English Channel); L. scottorum sp. nov. from the Firth of Forth (Scotland), L. sarsi sp. nov. from the southern and northern coasts of Norway, L. gertraudae sp. nov. from the Chilean Patagonian continental slope and L. monsmaris sp. nov. from the Great Meteor Seamount (NE Atlantic). Additionally, the reexamination of the redescription of L. typicus from the northern Norwegian coast (Sars 1908) resulted in the detection of $L$. norvegicus sp. nov.

Species identification and drawings were made with the use of a camera lucida on a Leica DMR compound microscope equipped with differential interference contrast. For the identification of species, the keys provided by Lang (1948), Wells (2007) and Kornev \& Chertoprud (2008) as well as original descriptions were used. General terminology follows Lang (1948), Huys \& Boxshall (1991) and Huys et al. (1996). Terminology referring to phylogenetic aspects follows Ax (1984); the terms 'telson' and 'furca' are adopted from Schminke (1976). Differentiation between the body sections is as follows: cephalothorax (including A1-P1); thorax (P2-P6-bearing somites); abdomen (genital somite-telson). Differentiation between pro- and urosoma is not made.

Abbreviations used in the text
$\begin{array}{ll}\text { A1 } & \text { antennule } \\ \text { A2 } & =\text { antenna } \\ \text { aes } & =\text { aesthetasc } \\ \text { benp } & =\text { basendopod } \\ \text { cphth } & =\text { cephalothorax }\end{array}$




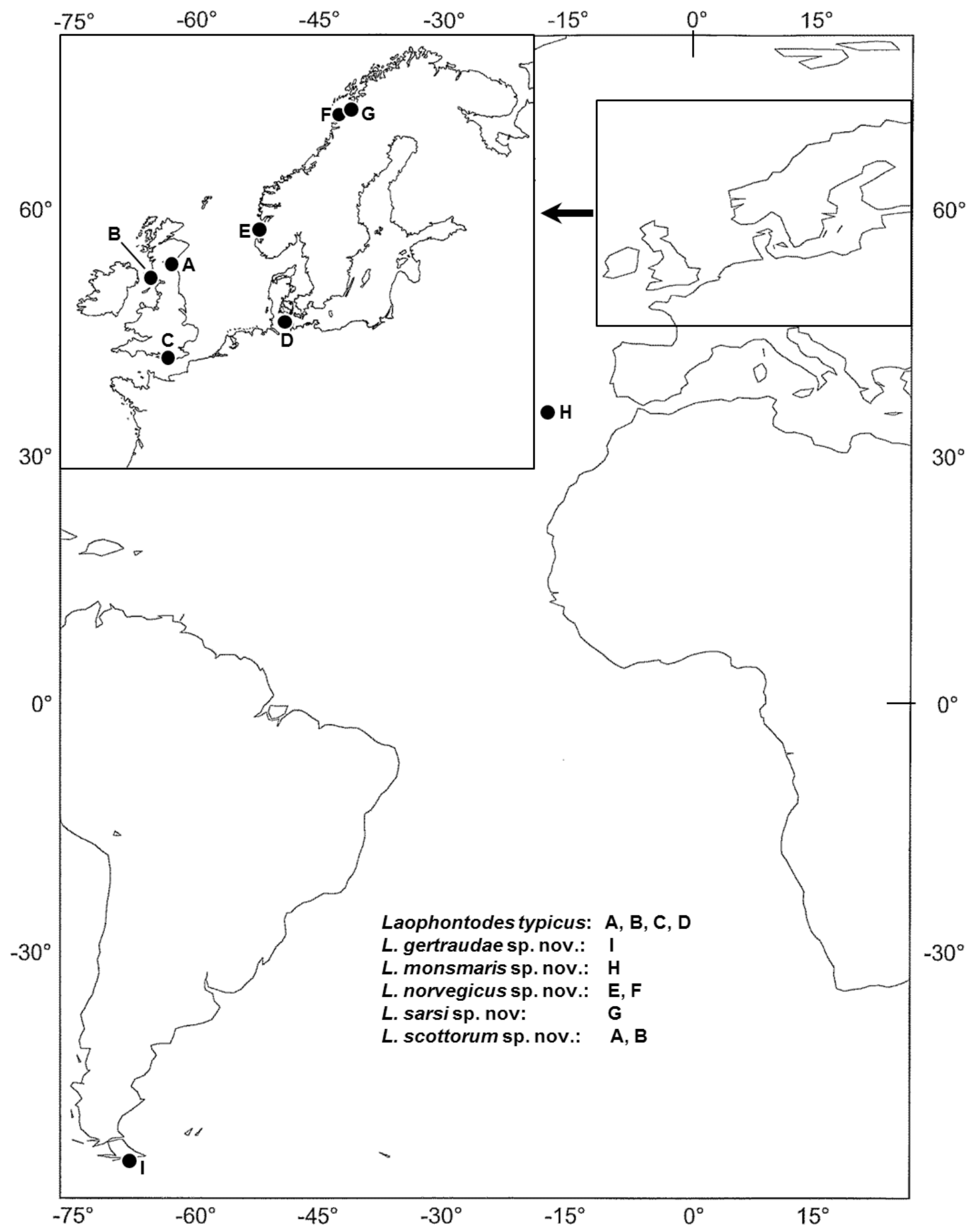

Fig. 1. Map of reported localities for species treated in the present contribution. A = Firth of Forth, Scotland (UK); B = Firth of Clyde, Scotland (UK); C = coast of Sussex (UK); D = Bight of Kiel (Germany); $\mathrm{E}=$ Bukken (Norway); $\mathrm{F}=$ Salten fjord (Norway); $\mathrm{G}=$ Skjerstad fjord (Norway); $\mathrm{H}=$ Great Meteor Seamount; I = Isla Nueva, Chile. 


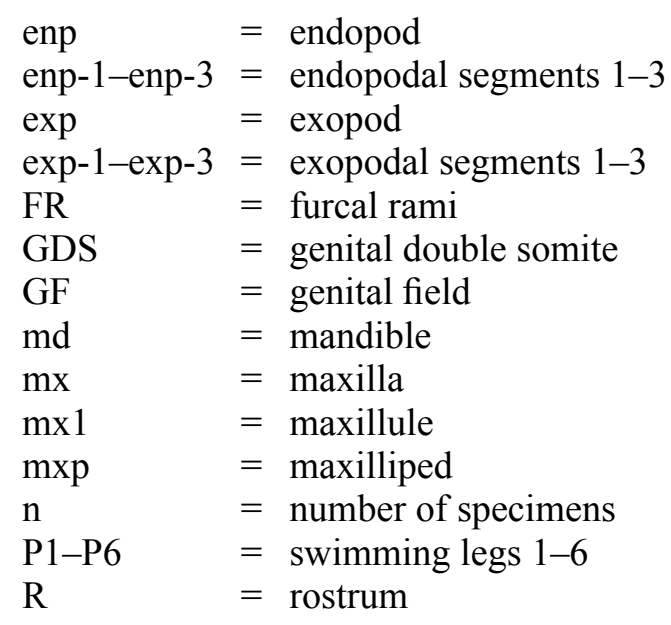

\title{
Museum acronyms
}

BMNH $=$ Natural History Museum, London, UK

NHM = Natural History Museum of the University of Oslo, Norway

SMF = Senckenberg Forschungsinstitut und Naturmuseum, Frankfurt am Main, Germany

\section{Results}

\author{
Subclass Copepoda Milne-Edwards, 1840 \\ Order Harpacticoida Sars, 1903 \\ Family "Ancorabolidae" Sars, 1908 \\ Subfamily Laophontodinae Lang, 1944
}

Genus Laophontodes T. Scott, 1894

The taxon comprises 14 species (cf. George \& Gheerardyn 2015; George 2017). Type species: L. typicus T. Scott, 1894. Additional species: L. bicornis A. Scott, 1896, L. gracilipes Lang, 1936, L. hamatus (Thomson, 1882), L. horstgeorgei George \& Gheerardyn, 2015, L. macclintocki Schizas \& Shirley, 1994, L. mourois Arroyo, George, Benito \& Maldonado, 2003, L. multispinatus Kornev \& Chertoprud, 2008, L. ornatus Krishnaswamy, 1957, L. propinquus Brady, 1910, L. sabinegeorgeae George \& Gheerardyn, 2015, L. spongiosus Schizas \& Shirley, 1994, L. whitsoni T. Scott, 1912; species incertae sedis: L. antarcticus Brady, 1918. An amended generic diagnosis was recently provided by George \& Gheerardyn (2015). The setation of swimming legs is summarized for all redescribed species in Table 1.

\section{Redescription of Laophontodes typicus T. Scott, 1894}

Figs 2-6

\section{Locus typicus}

UNITED KINGDOM: Scottish Firth of Forth, "Vicinity of Inchkeith” (T. Scott 1894: 250).

\section{Type material}

Not available anymore.

\section{Material examined (no types)}

UNITED KINGDOM: 35 우, 11 $\hat{\jmath}$, Sussex coast (eastern English Channel), Whirlpool Hole, $50^{\circ} 41.40^{\prime} \mathrm{N}, 00^{\circ} 48.85^{\prime} \mathrm{W}, 19.6 \mathrm{~m}$ depth, 7 Sep. 1997, Dr David Ventham leg., preserved in ethanol (BMNH 2015.1144-1153) (for detailed sampling data see Ventham 2011: 35). 
Table 1. Setation of female P2-P4 exps and enps for the 6 Laophontodes species examined. Bold numbers $=$ derived states; grey-marked fields $=$ most derived states. Arabic numerals indicate inner setae; Roman numerals indicate outer spines. *According to Scott (1907).

\begin{tabular}{|c|c|c|c|c|c|c|}
\hline \multirow{2}{*}{ Species/appendage } & \multicolumn{2}{|c|}{$\mathbf{P 2}$} & \multicolumn{2}{|c|}{ P3 } & \multicolumn{2}{|c|}{ P4 } \\
\hline & Exopod & Endopod & Exopod & Endopod & Exopod & Endopod \\
\hline Laophontodes typicus T. Scott, 1894 & $\begin{array}{c}\text { 0-I/0-I/1- } \\
\text { 2-III }\end{array}$ & $0 / 0-2-0$ & $\begin{array}{c}\text { 0-I/0-I/1- } \\
\text { 2-III }\end{array}$ & $0 / 1-2-0$ & $\begin{array}{c}0-\mathrm{I} / 0-\mathrm{I} / \mathbf{1}- \\
2-\mathrm{III}\end{array}$ & $0 / 1-2-0$ \\
\hline Laophontodes scottorum sp. nov. & $\begin{array}{c}0-\mathrm{I} / 0-\mathrm{I} / \mathbf{0}- \\
\text { 2-III }\end{array}$ & $0 / 0-2-0^{*}$ & $\begin{array}{c}0-\mathrm{I} / 0-\mathrm{I} / \mathbf{0}- \\
2-\mathrm{III}\end{array}$ & $0 / 1-2-0$ & $\begin{array}{c}0-\mathrm{I} / 0-\mathrm{I} / \mathbf{0}- \\
2-\mathrm{III}\end{array}$ & $0 / 1-2-0$ \\
\hline Laophontodes sarsi sp. nov. & $\begin{array}{c}0-\mathrm{I} / 0-\mathrm{I} / \mathbf{0}- \\
\text { 2-III }\end{array}$ & $0 / 0-2-0$ & $\begin{array}{c}0-\mathrm{I} / 0-\mathrm{I} / \mathbf{0}- \\
2-\mathrm{III}\end{array}$ & $0 / 1-2-0$ & $\begin{array}{c}0-\mathrm{I} / 1-\mathrm{I} / \mathbf{0}- \\
2-\mathrm{III}\end{array}$ & $0 / 1-2-0$ \\
\hline Laophontodes norvegicus sp. nov. & $\begin{array}{c}0-\mathrm{I} / 0-\mathrm{I} / \mathbf{0}- \\
2-\mathrm{III}\end{array}$ & $0 / 0-2-0$ & $\begin{array}{c}0-\mathrm{I} / 0-\mathrm{I} / \mathbf{0}- \\
2-\mathrm{III}\end{array}$ & $0 / 1-2-0$ & $\begin{array}{c}0-\mathrm{I} / 0-\mathrm{I} / \mathbf{0}- \\
2-\mathrm{III}\end{array}$ & $-/ 1-2-0$ \\
\hline Laophontodes gertraudae sp. nov. & $\begin{array}{c}0-\mathrm{I} / 0-\mathrm{I} / \mathbf{0}- \\
2-\mathrm{III}\end{array}$ & $0 / 0-2-0$ & $\begin{array}{c}0-\mathrm{I} / 0-\mathrm{I} / \mathbf{0}- \\
2-\mathrm{III}\end{array}$ & $0 / \mathbf{0}-2-0$ & $\begin{array}{c}0-\mathrm{I} / 0-\mathrm{I} / \mathbf{0}- \\
2-\mathrm{III}\end{array}$ & $0 / \mathbf{0}-2-0$ \\
\hline Laophontodes monsmaris sp. nov. & $\begin{array}{c}0-\mathrm{I} / 1-\mathrm{I} / 1- \\
2-\mathrm{III}\end{array}$ & $0 / 0-2-0$ & $\begin{array}{c}0-\mathrm{I} / 1-\mathrm{I} / 2- \\
2-\mathrm{III}\end{array}$ & $0 / \mathbf{0}-2-0$ & $\begin{array}{c}0-\mathrm{I} / 1-\mathrm{I} / 2- \\
2-\mathrm{III}\end{array}$ & $0 / 1-2-0$ \\
\hline
\end{tabular}

For the redescription, 2 q $ᄋ$ were dissected and distributed over 4 and 5 slides, respectively, embedded in glycerol. Additionally, $2 \widehat{\partial} \widehat{\partial}$ were each mounted on 1 slide, but subsequently returned into ethanol.

\section{Description}

\section{Female}

Habitus (Fig. 2A-B). Cylindrical, tapering distally, body length ( $\mathrm{R}$ to end of FR) $388 \mu \mathrm{m}$. Cphth slightly longer than broad, representing $25 \%$ of body length. R (Figs $2 \mathrm{~A}, 3 \mathrm{~A}$ ) small, fused to cphth, with 2 sensilla on apical margin. Body somites clearly distinct. Posterior margins of thoracic somites serrated dorsally, with sensilla arising from small socles and with 1 tube pore centrally; P2-P4-bearing somites additionally with fine ripples running anteriorly. Last thoracic and first abdominal somites fused to form genital double somite, juncture detectable by dorsal serration and constricted outer margins. Abdominal part of GDS and following two abdominal somites dorsally strongly serrated. Penultimate somite without sensilla but with pair of tube pores. Telson slightly smaller than preceding somite, with FR widely separated proximally. Anal operculum with spinules of moderate length on apical margin.

FuRCAL RAMI (Fig. 2A-C). Slender, about 6 times longer than its broadest part, proximally with tube pore and with 7 bare setae: I and II of almost same length, arising centrally from outer margin; III subapical on dorsal side; IV and V apical, IV very narrow and less than half of the length of V; VI apical on inner margin, as long as I-III; VII slightly longer than IV, dorsal, arising from pedestal, tri-articulated at base.

ANTENNUle (Fig. 3A-A'). 5-segmented. First segment (Fig. 3A) carrying 1 bipinnate seta and a row of spinules around apical edge; second segment (marked with * in Fig. 3A-A') with spinulose bump at posterior margin and 9 bare setae; third segment as long as second, with 7 bare setae and 1 aes; fourth segment smallest, partially overlapped by preceding segment, with 1 bare seta; fifth segment with 9 bare setae, 6 of which bi-articulated at base; apically with small aes and 2 additional setae forming a trithek.

SETAL FORMULA. 1-1/2-9/3-7+aes/4-1/5-11+aes. 

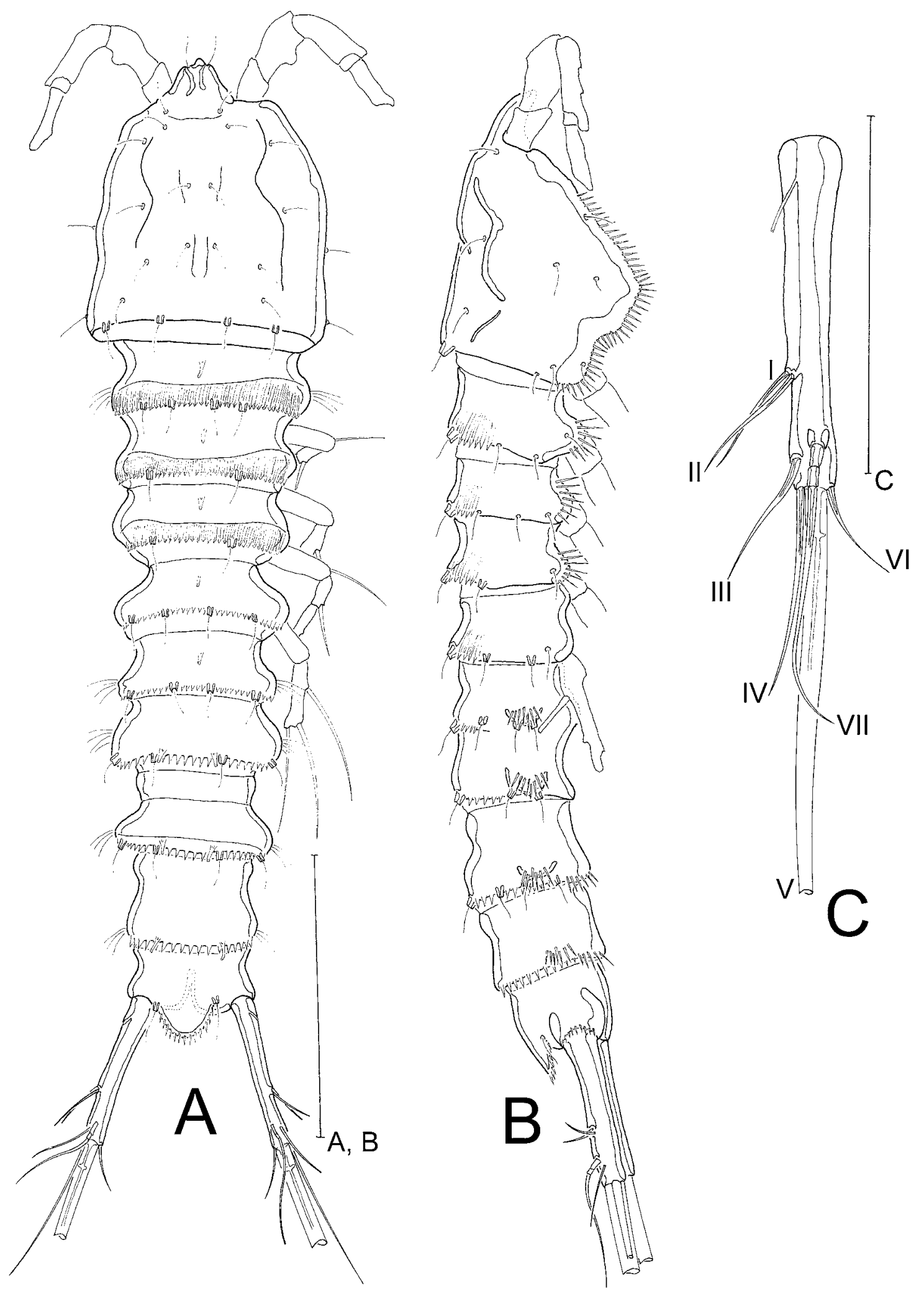

Fig. 2. Laophontodes typicus T. Scott, 1894. A-C. Habitus + (BMNH 2015.1144-1153-1). A. Dorsal view. B. Lateral view. C. Left furcal ramus, dorsal view. Scale bars: A-B $=100 \mu \mathrm{m}, C=50 \mu \mathrm{m}$. 


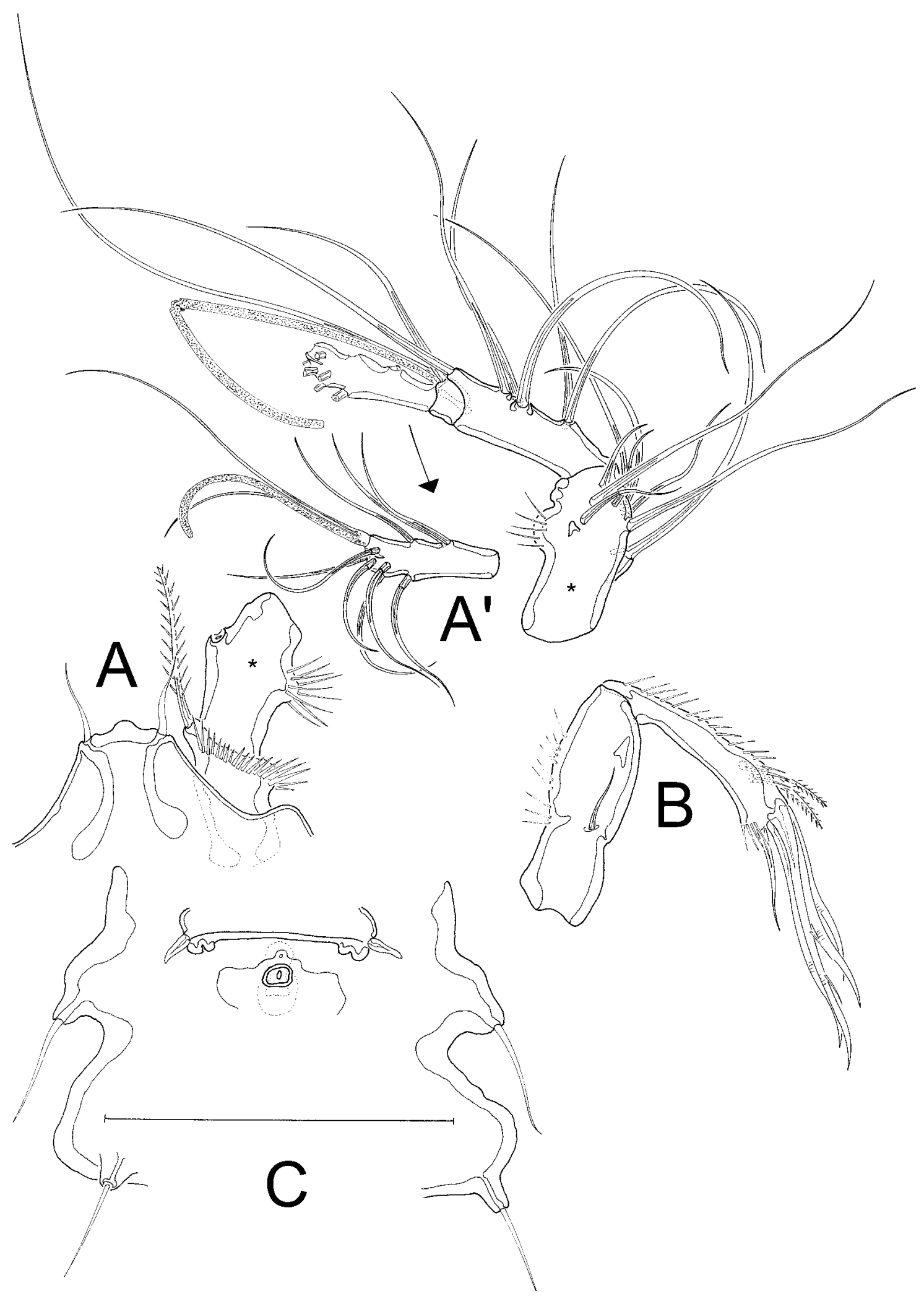

Fig. 3. Laophontodes typicus T. Scott, 1894, ㅇ (A-B: BMNH 2015.1144-1153-1; A', C: BMNH 2015.1144-1153-3). A. Rostrum, first and second segment of A1. A'. Second to fifth segments of A1. Asterisk (*) showing second segment. B. A2. C. Genital double somite with genital field and P6. Scale bar $=50 \mu \mathrm{m}$. 


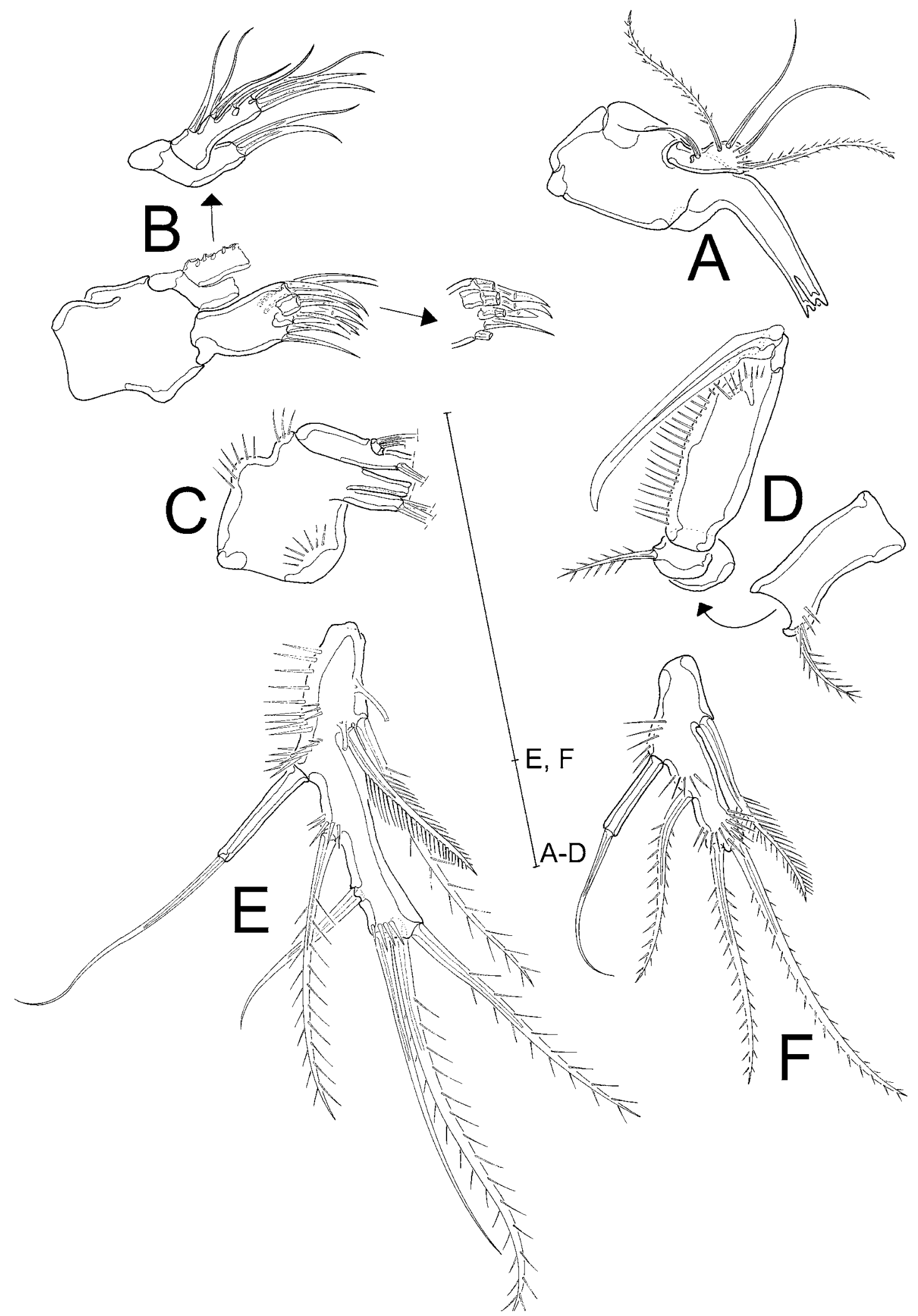

Fig. 4. Laophontodes typicus T. Scott, 1894, A-E. \& (A-D: BMNH 2015.1144-1153-1; E: BMNH 2015.1144-1153-3). A. Md B. Mxl. C. Mx. D. Mxp. E. P5. F. ô (BMNH 2015.1144-1153-2), P5. Scale $\mathrm{bar}=50 \mu \mathrm{m}$. 
Antenna (Fig. 3B). Allobasis lacking abexopodal seta but with abexopodal row of spinules. Exp represented by 1 bare seta. Enp shorter than allobasis, with row of subapical spinules, row of anterior spinules, 2 bipinnate anterior setae and 5 bare apical setae, of which 4 geniculated.

Mandible (Fig. 4A). With slender gnathobase bearing 5 teeth; palp 1-segmented, with 4 lateral setae (1 bipinnate) and 1 bipinnate terminal seta.

MAXILlule (Fig. 4B). Praecoxal arthrite distinct, with 7 strong bare spines, of which two bi-articulated, 1 subapical seta and 2 additional surface setae. Coxa without spinules, 2 bare setae terminally. Basis without spinules, 3 bare setae terminally, and 1 bare seta medially between the enp and the basal endite. Exp and enp represented by 1 and 2 bare setae, respectively.

Maxilla (Fig. 4C). Damaged; all setae broken. Syncoxa bearing 3 rows of spinules and 2 endites. Proximal endite with 2 bare setae (broken in Fig. 3C); setation of distal endite not discernible. Basis distinct, produced into strong claw (?), with 1 seta (broken in Fig. 3C). Enp small; with 2 bare setae (both broken in Fig. 3C).

MAXILLIPED (Fig. 4D). Prehensile; syncoxa slightly shorter than basis, with spinules and 1 bipinnate seta distally. Basis with long spinules along inner margin and subapically. Enp transformed into claw, nearly same length as basis; if accompanying minute seta present, not discernible.

Swimming Legs. P1 (Fig. 5A) with square coxa; basis slightly longer than coxa, with 1 bipinnate outer seta and 1 uniplumose seta displaced to anterior surface. Enp 2-segmented, enp-1 strong and elongated, with row of spinules on outer and inner margins; enp-2 small, $1 / 3$ length of enp-1, apically with 1 claw and 1 slender geniculated bare seta, subapically with 1 small seta. Exp 3-segmented, reaching more than half the length of enp-1. Exp-1 with 1 uniplumose outer seta; exp-2 with outer row of spinules and 1 bare geniculated outer seta; exp-3 apically with 4 long bare geniculated setae. P2-P4 (Fig. 5B-D) with transversely elongated bases, 3-segmented exopods and 2-segmented endopods. Exp-3 longest segment, all segments with row of spinules on outer margins. Exp-1 and exp-2 without inner seta but with 1 bipinnate outer spine; Exp-3 with 1 bare inner seta and 3 outer spines; P2 exp-3 apically with 1 biplumose outer seta and 1 bare inner seta; $\mathrm{P} 3$ and $\mathrm{P} 4$ exp-3 with 2 biplumose apical setae. P2-P4 enp-1 small, without setae. P2 enp-2 elongated, with 2 biplumose apical setae; P3 and P4 enp-2 as in P2 with additional bare inner seta, which is comparatively small in P4. P5 (Fig. 4E) benp represented by 2 setae, one biplumose and one of fish-bone aspect, accompanied by 2 tube pores. Benp on outer apical margin with long setophore surrounded by long spinules, bearing 1 bare seta. Exp fused to benp, slender, with 2 outer setae, one of which bare, the other biplumose, 1 biplumose subapical and 2 apical setae, one bare, the other biplumose.

GeNITAL FIELD (Fig. 3C). With single gonopore; P6 strongly reduced, limbs fused as small single plate, with pair of small bare spines.

\section{Male}

The male differs from the female in the following characters: body size, A1, P3 endopod, P5.

HaBitus (Fig. 6A). As in female, but slightly smaller and narrower (body length of described specimen from rostral tip to end of FR: $337 \mu \mathrm{m}$ ); no GDS.

Antennule (Fig. 6B-B'). 6-segmented, chirocer. First segment as broad as long, apically with row of spinules and 1 bipinnate seta; second segment with spinulose bump along posterior margin, several spinules on inner proximal part and 8 bare setae; third segment small, with 4 bare setae; fourth segment smallest, with 1 seta; fifth segment slightly swollen, with 6 bare setae and 1 cuspidate spine on its ventral 


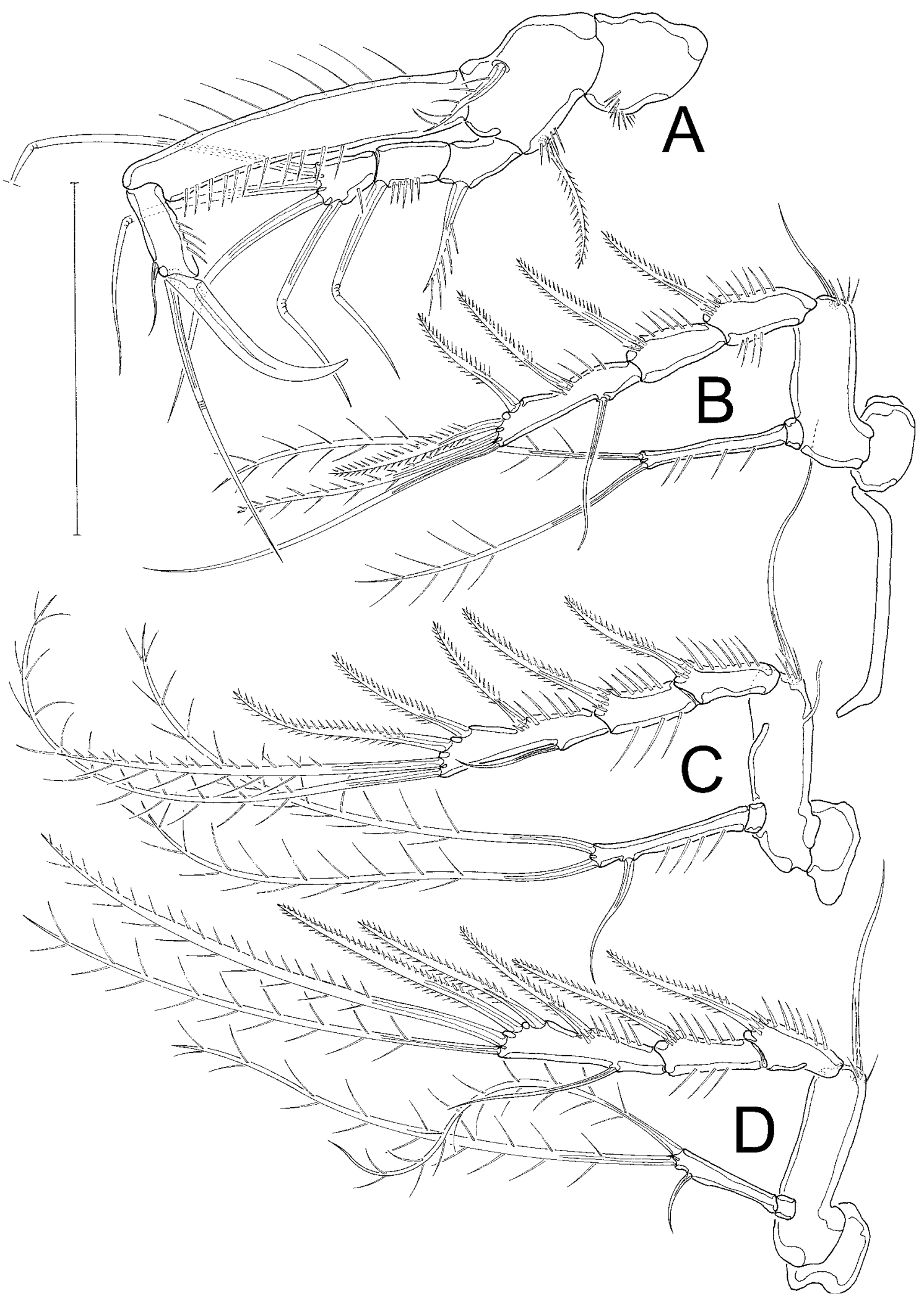

Fig. 5. Laophontodes typicus T. Scott, 1894, $q$ (BMNH 2015.1144-1153-1). A. P1. B. P2. C. P3. D. P4. Scale bar $=50 \mu \mathrm{m}$. 


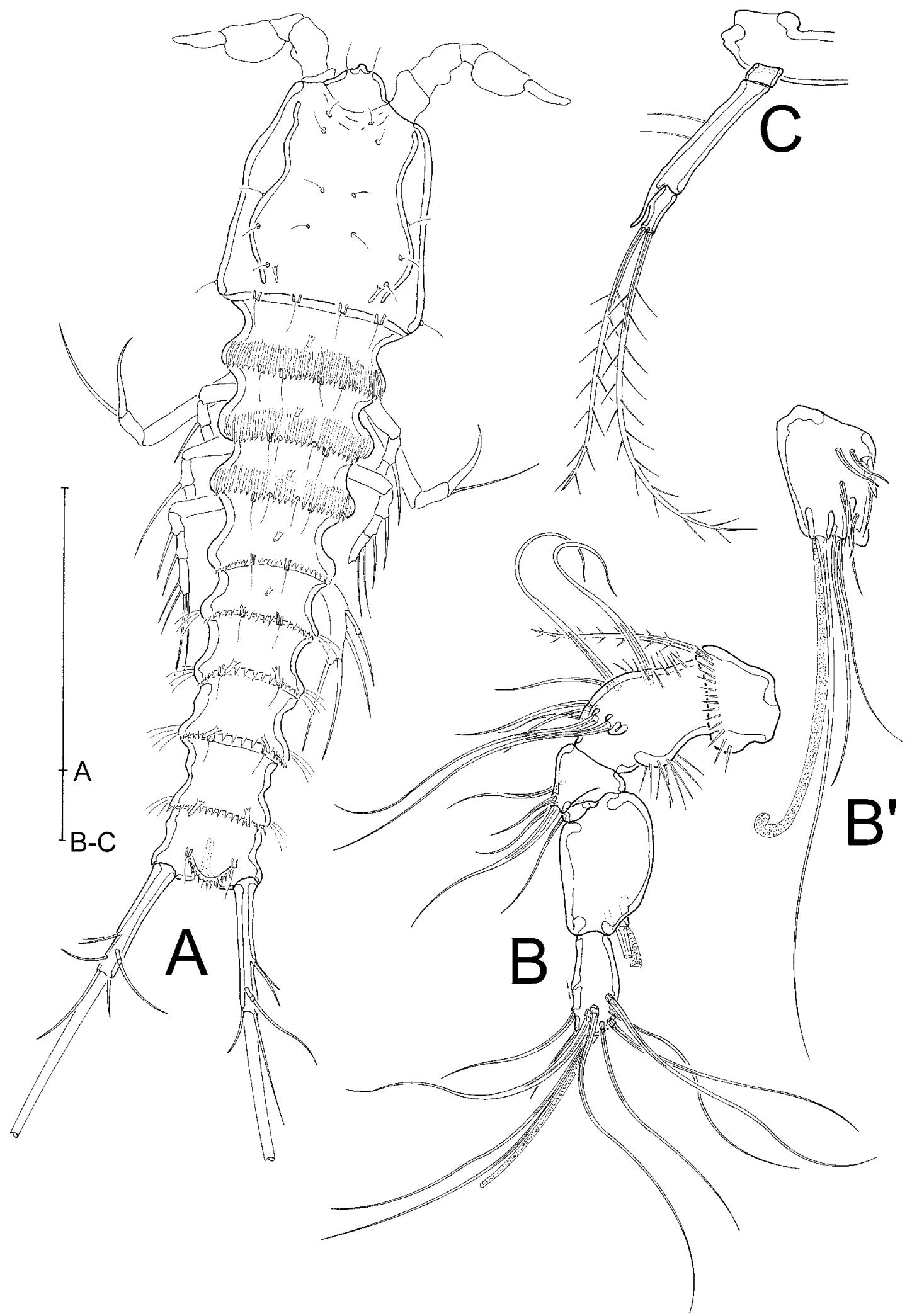

Fig. 6. Laophontodes typicus T. Scott, 1894, đ̊ (A: BMNH 2015.1144-1153-2; B-C: BMNH 2015.11441153-4). A. Habitus, dorsal view. B. A1. B'. Fifth segment of A1 showing setation. C. P3 enp. Scale bar: $\mathrm{A}=100 \mu \mathrm{m}, \mathrm{B}-\mathrm{C}=50 \mu \mathrm{m}$. 
surface (Fig. 5B'), and apically with 2 long bare setae and 1 aes accompanied by 1 bare seta on pedestal (Fig. 5B'); sixth segment with 9 bare setae (1 seta broken in Fig. 6B), and 1 aes arising together with 2 bare setae to form an apical trithek.

SETAL FORMULA. 1-1/2-8/3-4/4-1/5-10+aes/6-11+aes.

Swimming Legs. P3 (Fig. 6C) exp as in female. Enp 3-segmented: Enp-1 small and unarmed; enp-2 longest, without setae but with thorn-like, slightly curved apophysis on inner apical margin; enp-3 not reaching end of enp-2 apophysis, with 2 biplumose apical setae. P5 (Fig. 4F) small, benp and exp fused. Benp with outer basal seta arising from setophore. Endopodal lobe represented by 1 biplumose seta. Exp short, with 1 bipinnate outer seta and 2 bipinnate apical setae; no tube pores discernible.

Laophontodes scottorum sp. nov. urn:1sid:zoobank.org:act:9A5CB956-4F5E-4928-BA06-A29001DC3E97

Figs 7-8

\section{Etymology}

The epitheton 'scottorum' is given in respectful remembrance of Thomas Scott, who firstly described L. typicus, and of his son Andrew Scott, who provided the illustrations.

\section{Type material}

\section{Holotype}

UNITED KINGDOM:, , the Scottish Firth of Forth, labelled as [co-type, collection Norman, collection number BMNH 1911.11.8.44995].

Dissection not permitted owing to single individual: description based on intact specimen resulting in certain perspective-related bias and preventing examination of some appendages. Uncertainty with an observation is denoted with (?). Male partially described by T. Scott (1907) (as L. typicus).

\section{Description}

\section{Female}

HaBitus (Fig. 7A). Slightly flattened dorsoventrally and longitudinally compressed, body length (R to end of FR) $438 \mu \mathrm{m}$. Cphth as long as broad, $1 / 3$ of body length. R small, fused to cphth, with 2 sensilla on apical margin. Posterior margin of cphth extended laterally, rounded at outer margin and carrying fine setular tufts. Pedigerous somites $1-4$ about 4.5 times as broad as long, clearly distinct, laterally extended, with setular tufts on outer lateral margins. Posterior margins serrated dorsally and with fine ripples running anteriorly; additionally with sensilla arising from small socles and 1 tube pore centrally. Genital double somite formed by fusion of last thoracic and first abdominal somites, juncture detectable by serration, sensilla-bearing socles and constricted outer margins; abdominal half with pair of tube pores on distal margin. Second and third abdominal somites remarkably smaller than thoracic and first abdominal somites, being about 3.5 times as broad as long; posterior margins similarly serrated and with fine ripples running anteriorly, second somite also with pair of tube pores on distal margin and with sensilla-bearing socles, third somite lacking sensilla and tube pores. Telson 2.9 times as broad as long, FR arising widely separated. Anal operculum broad, with moderately long spinules at apical margin (several spinules broken in Fig. 7A).

FurCAL RAMI (Fig. 7A-B). Slender, about 3.8 times longer than broadest point, proximally with tube pore, and with 7 setae: I and II arising centrally from outer margin, II being twice as long as I; III slightly smaller than II, subapically at dorsal side; IV and V apical, IV very narrow and less than half the length of V; VI apical at inner margin, as long as I; VII dorsal, arising from pedestal, tri-articulated at base. 


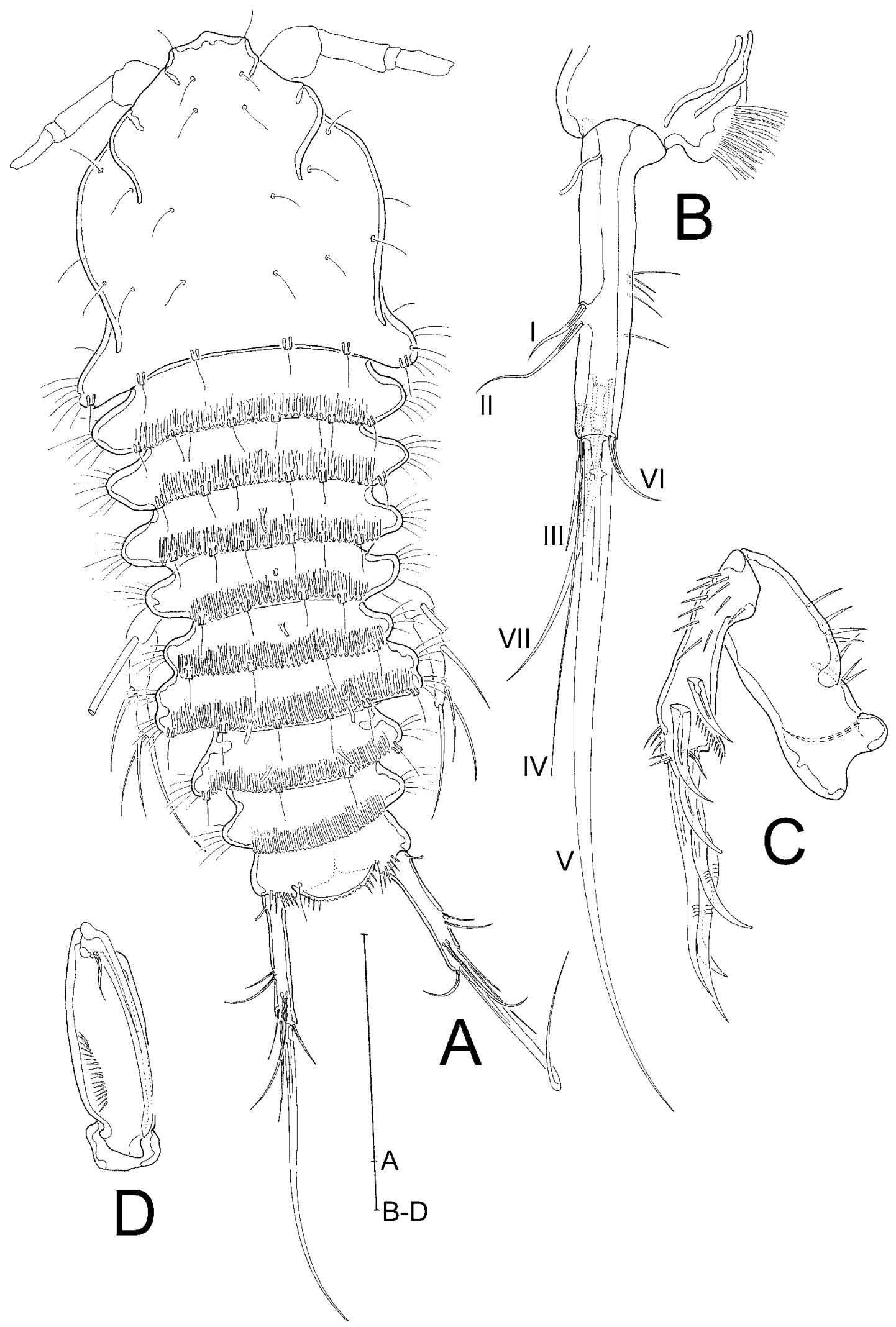

Fig. 7. Laophontodes scottorum sp. nov., holotype, $q$ (BMNH 1911.11.8.44995). A. Habitus, dorsal view. B. Right furcal ramus, ventral view. C. A2. D. Mxp. Scale bar: A $=100 \mu \mathrm{m}, \mathrm{B}-\mathrm{D}=50 \mu \mathrm{m}$. 


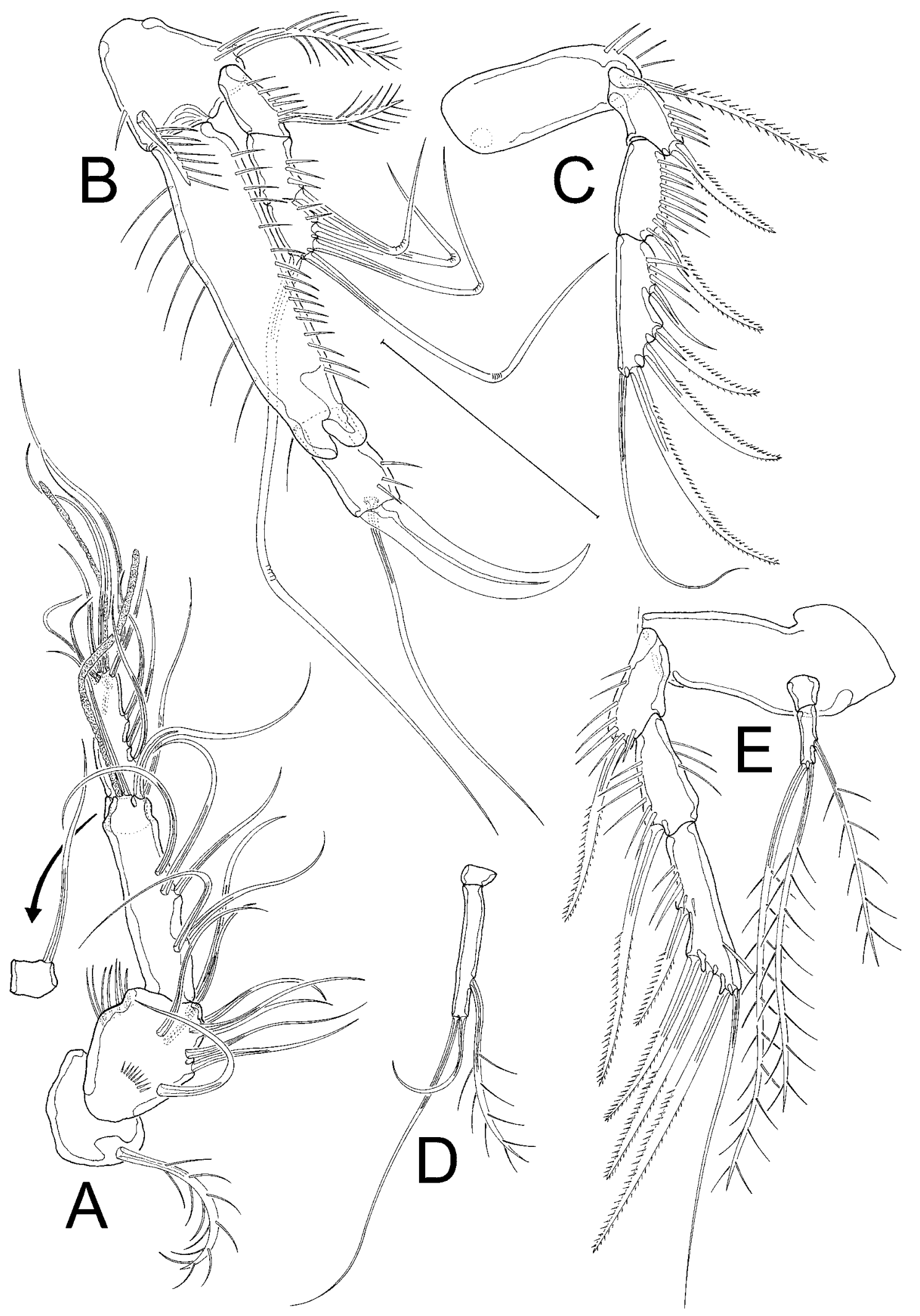

Fig. 8. Laophontodes scottorum sp. nov., holotype, $q$ (BMNH 1911.11.8.44995). A. A1. B. P1. C. P2, dotted circle marking apparent position of enp. D. P3. E. P4. Scale bar $=50 \mu \mathrm{m}$. 
Antennule (Fig. 8A). 5-segmented. First segment with 1 biplumose seta; second segment with 9 bare setae; third segment longest (?), equipped with 7 bare setae and 1 aes; fourth segment overlapped by preceding one, with 1 bare seta; fifth segment with 10 bare setae and small apical aes.

SetAL FORMULA. 1-1/2-9/3-7+aes/4-1/5-10+aes.

AnTENNA (Fig. 7C). Sturdy, enp slightly shorter than allobasis, exp represented by small bare seta. Allobasis without abexopodal seta, but with abexopodal row of spinules. Enp with several spinules, 2 bare spines plus 1 minute seta on distal edge, and 4 strong geniculate setae and 1 spine apically; subapical denticulate frill.

MD, MxL AND Mx. Not examined.

MAXILLIPED (Fig. 7D). Syncoxa partially obscured; basis with row of spinules; enp formed into strong claw, same length as enp, with minute bare seta.

Swimming Legs. P1 (Fig. 8B) coxa obscured; basis triangular with 1 biplumose outer seta and 1 uniplumose inner seta displaced to anterior surface. Enp 2-segmented, enp-1 strong, elongated, with row of spinules on both outer and inner margin; enp- 2 small, $1 / 3$ length of enp-1, with large claw and 1 long, slender bare seta apically, small seta not discernible. Exp 3-segmented, less than half the length of enp, each segment with spinules on outer margin, also exp-1 with 1 biplumose outer seta; exp-2 with 1 long, bare and geniculate outer seta; exp-3 with 4 long, bare geniculate setae. P2-P4 (Fig. 8C-E) with transversely elongated bases, 3-segmented exopods and 2-segmented endopods (not discernible in P2). Exopodal segments increasing in size from exp-1 to exp-3, each segment with row of spinules on outer margin, no inner setae. Exp-1 and exp-2 with 1 bipinnate outer spine; exp-3 with 3 outer spines, and apically with 1 outer spine and 1 slender flexible and bare inner seta. P2 enp (Fig. 8C) missing or broken, not drawn. P3 enp-1 very small and bare; enp-2 about 7 times longer than enp-1, with 1 inner biplumose seta and 2 apical bare setae, inner apical seta half the length of outer apical seta (Fig. 8D). P4 enp small, enp-1 bare, enp-2 about twice as long as enp-1, with 1 inner and 2 apical setae, all biplumose (Fig. 8E). P5, GF, and P6 not examined, ventral urosome covered by detritus.

Laophontodes sarsi sp. nov. urn:1sid:zoobank.org:act:D78FE397-C13D-4AEF-96A8-A2AFE61829EE

Figs 9-11

\section{Etymology}

The epitheton 'sarsi' is given in respectful memory of Georg Ossian Sars, esteemed Norwegian scientist. who provided valuable contributions to our knowledge of Copepoda Harpacticoida, including the description of numerous species.

\section{Type material}

Two females collected and identified as Laophontodes typicus by G.O. Sars. Due to the limited number of (partially damaged) individuals, specimens were not dissected and, therefore, some appendages could not be observed or described.

\section{Holotype}

NORWAY: adult $q$, northern Norwegian coast, Skjerstad fjord, G.O. Sars leg., preserved in $75 \%$ ethanol (NHM F20298-1).

\section{Paratype}

NORWAY: adult $q$, same data as for holotype (NHM F20298-2). 


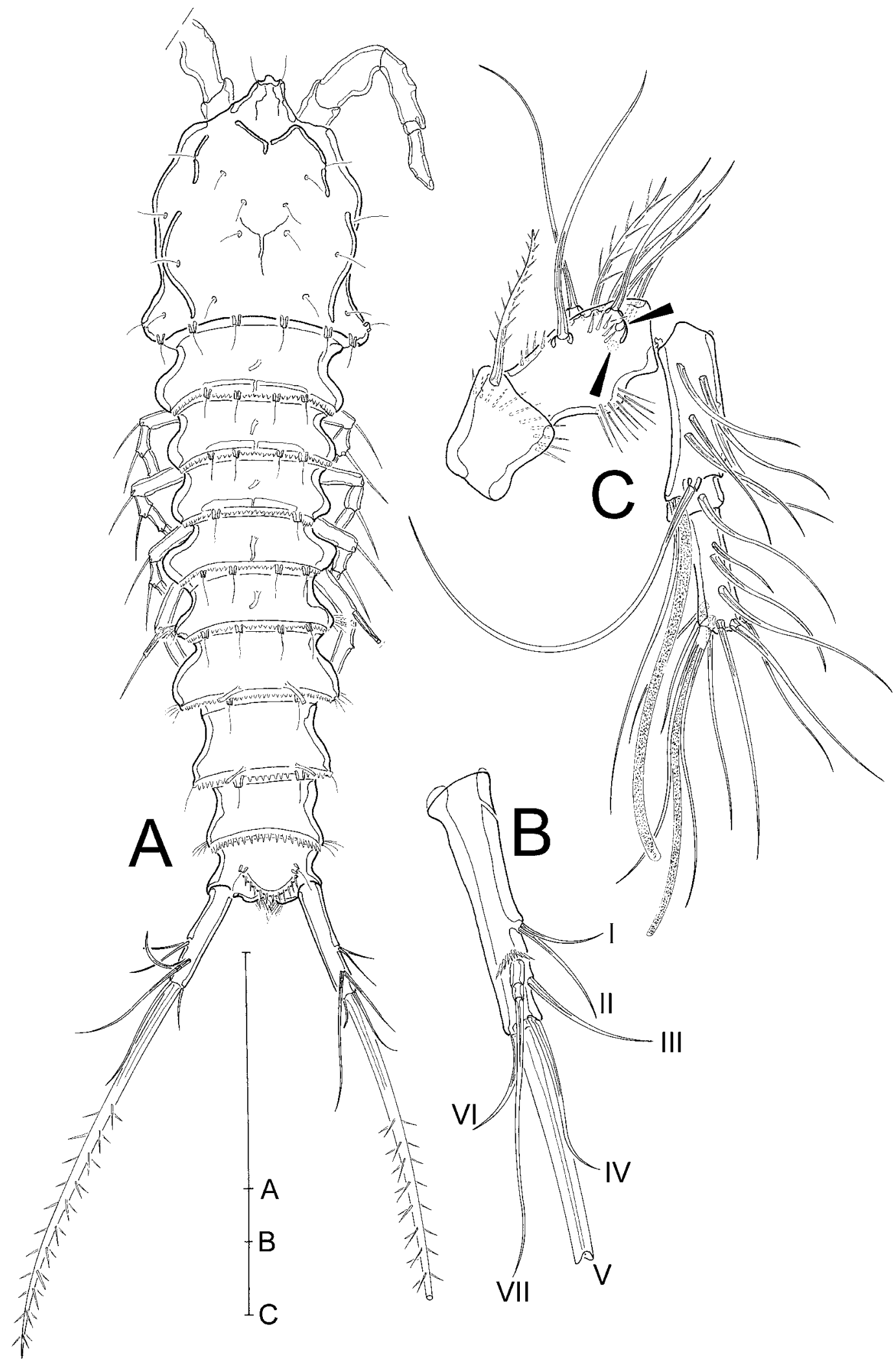

Fig. 9. Laophontodes sarsi sp. nov. A-B. Holotype, $q$ (NHM F20298-1). A. Habitus, dorsal view. B. Right furcal ramus, dorsal view. C. Paratype, ㅇ (NHM F20298-2), A1, triangular arrowheads marking broken setae. Scale bar: A $=100 \mu \mathrm{m}, \mathrm{B}-\mathrm{C}=50 \mu \mathrm{m}$. 


\section{Description}

\section{Female}

Habitus (Fig. 9A). Cylindrical, tapering distally, body length (R to end of FR) $387 \mu \mathrm{m}$ (female 1) and $350 \mu \mathrm{m}$ (female 2). Cphth slightly as long as broad, $25 \%$ of total body length, posteriorly with bulge on each side. R small, fused to cphth, with 2 sensilla on apical margin. Body somites distinct. Posterior margins of thoracic somites serrated dorsally, with sensilla arising from small socles and 1 tube pore centrally. Genital double somite formed by fusion of last thoracic and first abdominal somites, juncture detectable by dorsal serration and constricted outer margins. Abdominal part of GDS with finely serrated posterior margin and pair of tube pores; second and third abdominal somites dorsally strongly serrated at posterior margins; second somite with, third somite without sensilla-bearing socles and pair of tube pores. Telson slightly smaller than preceding somite, FR widely separated proximally. Anal operculum with pair of sensilla and moderately long spinules at apical margin.

FurCAL RAMI (Fig. 9A-B). Slender, about 3.7 times longer than its broadest part, proximally with tube pore (tube not discernible in Fig. 9B), and with 7 setae: I and II arising centrally from outer margin, II slightly longer than I; III subapical on dorsal side; IV and V apical, IV very narrow and less than half the length of V, which is tripinnate; VI apical on inner margin, as long as II; VII dorsal, tri-articulated at base, arising from pedestal, base surrounded by row of spinules.

Antennule (Fig. 9C). 5-segmented. First segment with 1 bipinnate seta and apical row of spinules; second segment with 9 setae ( 2 setae broken in Fig. 9C), one bipinnate; third segment with 7 bare setae and 1 aes; fourth segment partially overlapped by preceding one, with 1 bare seta; fifth segment with 9 bare setae, and 2 additional apical setae and small aes forming trithek.

Setal formula. 1-1/2-9/3-7+aes/4-1/5-11+aes.

ANTENNA (Fig. 10A). With enp slightly shorter than allobasis, exp represented by minute bare seta. Allobasis with 1 abexopodal seta and scant spinules. Enp with 2 rows of spinules, 2 bare spines and 1 minute seta on distal edge, 3 strong geniculate setae and 2 spines apically, and denticulate frill subapically.

MD, MxL AND Mx. Not drawn due to unfavourable position. However, unilobate md palp with 6 setae and $\mathrm{mx}$ with minute 1-segmented enp carrying 2 setae observed.

MAXILLIPED (Fig. 10B). With small syncoxa bearing 1 biplumose seta surrounded by small spinules; basis twice as long as syncoxa, with 1 row of spinules; enp (turned around in Fig. 10B) forming long claw with minute bare seta.

Swimming LEgs. P1 (Fig. 10C) with squarish coxa; basis as long as coxa, with 1 bipinnate outer seta and 1 uniplumose inner seta displaced to anterior surface. Enp 2-segmented, enp-1 elongated, with row of spinules on outer and inner margins; enp- 2 small, $1 / 3$ length of enp-1, apically with large claw, 1 long slender bare seta and 1 small seta. Exp 3-segmented, half the length of enp. All exopodal segments with spinules on outer margins; exp-1 with 1 uniplumose outer spine; exp-2 with 1 long bare geniculated outer seta; exp-3 with 4 long bare geniculated setae (innermost broken in Fig. 10C). P2-P4 (Fig. 11AC) with transversely elongated bases, 3-segmented exopods and 2-segmented endopods. Exp-3 longest, all segments with rows of spinules on outer margin; exp-1 and exp-2 with fine spinules sparsely on inner margin; P2 (Fig. 11A) and P3 (Fig. 11B) exps without inner seta; P4 (Fig. 11C) exp-1 and exp-3 without, exp-2 with 1 bare inner seta; $\mathrm{P} 2-\mathrm{P} 4$ exp-3 with 3 outer bipinnate spines, and apically with 1 bipinnate outer seta and 1 slender bare inner seta. P2-P4 enp-1 small, without setae. P2 enp-2 elongated, with spinules on outer and inner margins, and 2 biplumose apical setae; P3 and P4 enp-2 as in P2 (shorter in 

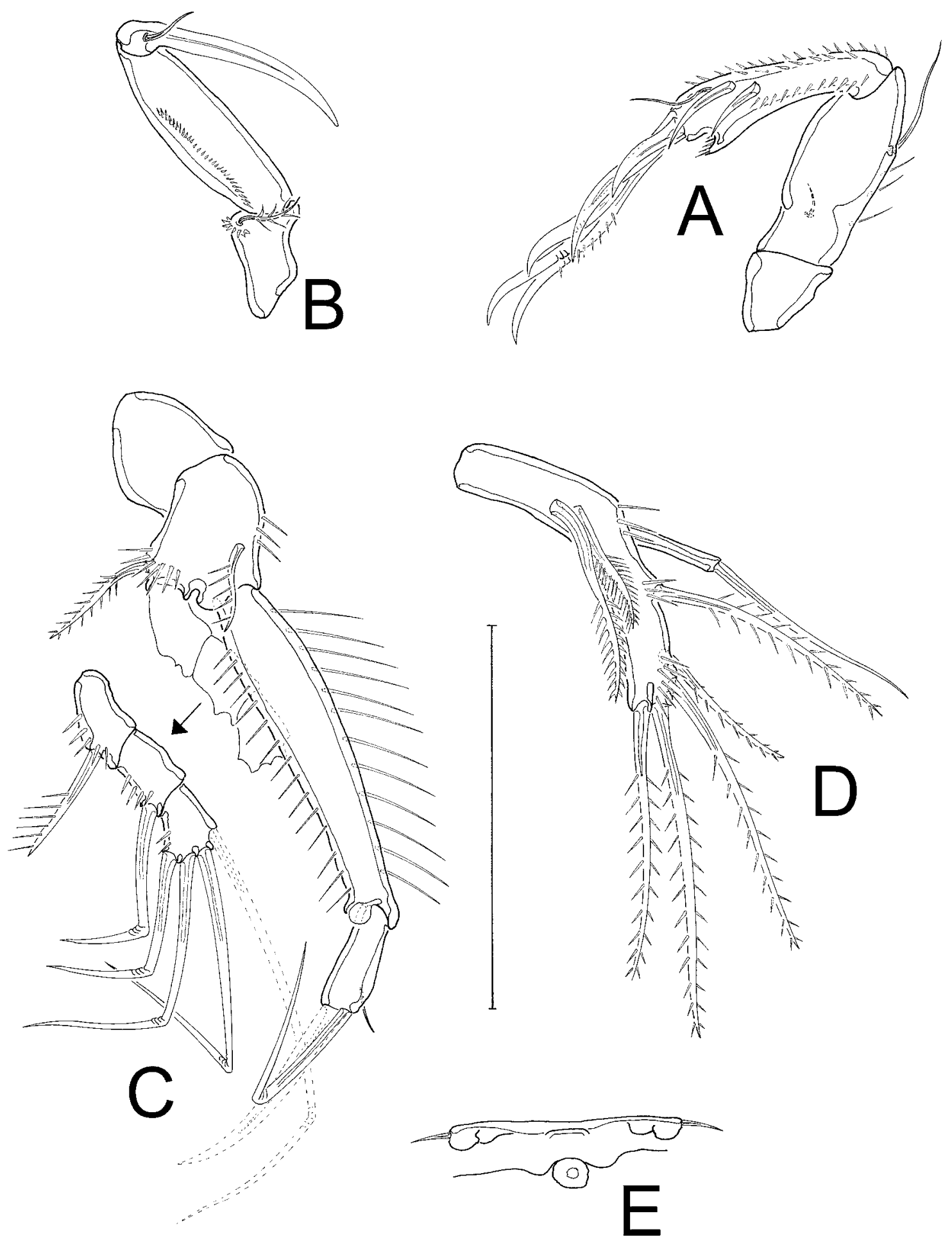

Fig. 10. Laophontodes sarsi sp. nov., paratype, $q$ (NHM F20298-2). A. A2. B. Mxp. C. P1, dotted elements according to counterpart. D. P5. E. GF with P6. Scale bar $=50 \mu \mathrm{m}$. 


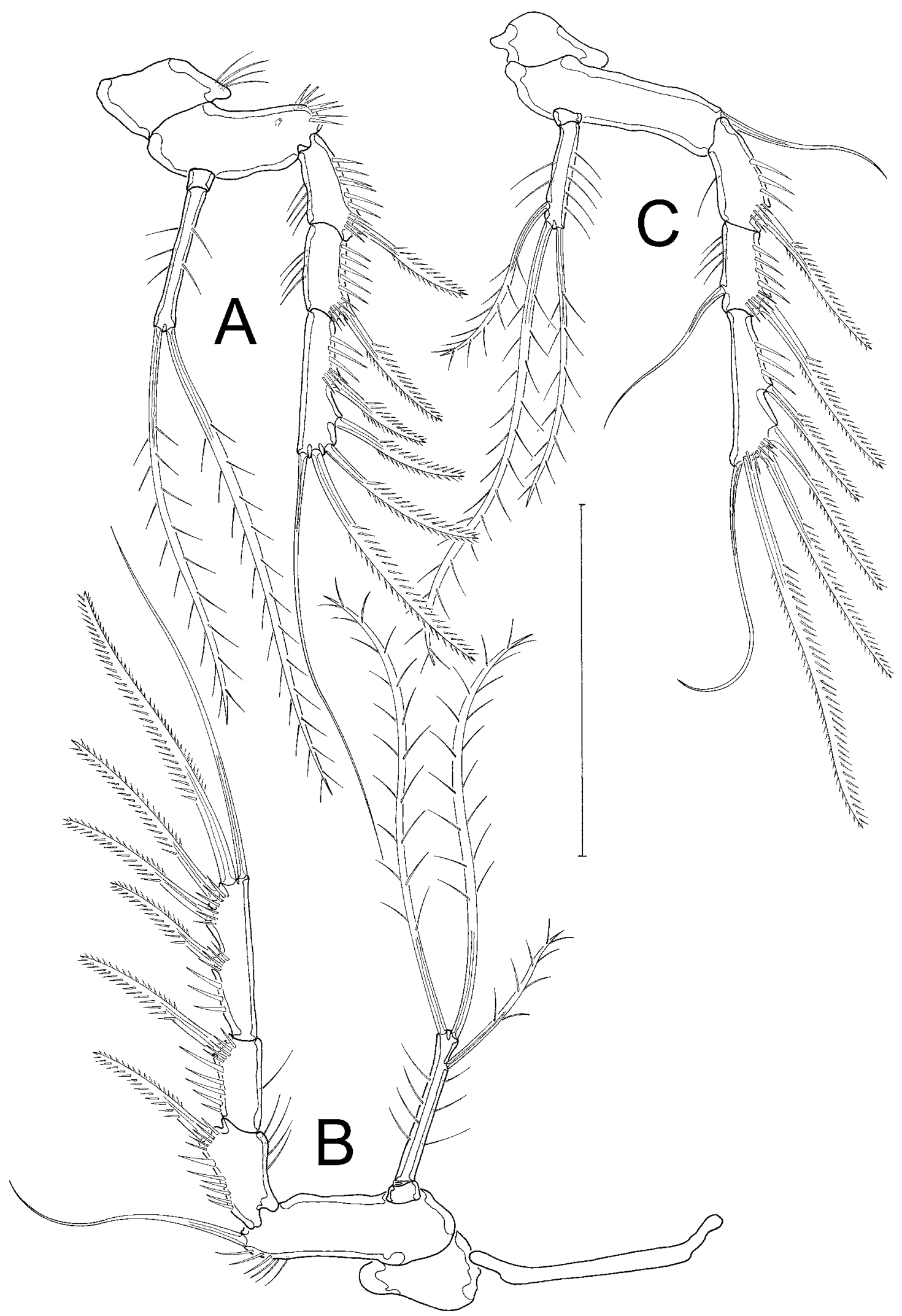

Fig. 11. Laophontodes sarsi sp. nov., holotype $q$ (NHM F20298-1). A. P2. B. P3. C. P4. Scale bar $=50 \mu \mathrm{m}$. 
P4), but additionally with 1 biplumose inner seta. P5 (Fig. 10D) small, benp and exp fused. Benp with outer basal seta arising from setophore. Endopodal lobe represented by 2 setae, one biplumose and one fish-bone. Exp short, with 2 outer, 1 subapical, and 2 apical setae, all bipinnate; no tube pores evident.

Genital Field (Fig. 10E). Small, with single gonopore; P6 strongly reduced, limbs fused forming a single small clasp, with pair of minute bare setae.

\section{Male \\ Unknown. \\ Laophontodes gertraudae sp. nov. urn:1sid:zoobank.org:act:B12998BE-6AFC-46F8-8836-B8C142FFCF20}

Figs $12-15$

\section{Etymology}

The epitheton 'gertraudae' is given in fond dedication to Mrs. Gertraud Schoetensack, Hannover (Germany).

\section{Type material}

Three females and three males collected during research cruise ANT XIII/4 of German RV POLARSTERN (Fahrbach \& Gerdes 1997). The material was originally determined as Laophontodes typicus by George $(1999,2005)$.

\section{Holotype}

CHILE: ${ }_{+}$, Chilean Patagonian continental slope, south off Isla Nueva, $55^{\circ} 26.5^{\prime} \mathrm{S}, 66^{\circ} 14.3^{\prime} \mathrm{W}$, station \#40/110, depth 105 m, Multicorer, 17 May 1996, K.H. George leg. (SMF 37114/1, on 1 slide).

\footnotetext{
Allotype

CHILE: ${ }^{\widehat{T}}$, collected with holotype (SMF 37115/1-9, on 9 slides).

\section{Paratypes}

CHILE: $1 \overbrace{}^{\lambda}, 1$ q, collected with holotype (SMF 37116/1, SMF 37117/1; on 2 slides); 1 ${ }^{\lambda}, 1$, , Chilean Patagonian continental slope, $55^{\circ} 47.8^{\prime} \mathrm{S}, 65^{\circ} 48.8^{\prime} \mathrm{W}$, station \#40/106, depth $2550 \mathrm{~m}$, Rauschert-Dredge, 15 May 1996, Martin Rauschert leg. (SMF 37118/1, SMF 37119/1; on 2 slides).
}

\section{Description}

Female

Habitus (Fig. 12A). Cylindrical, tapering distally, body length (R to end of FR) 317-380 $\mu \mathrm{m}(\mathrm{n}=3$ ), posteriorly with lateral bulges. Cphth slightly longer than broad, forming $1 / 3$ of total body length. $\mathrm{R}$ small (Figs 12A, 13A), fused to cphth, with 2 sensilla and 1 tube pore on apical margin. Body somites clearly distinct. Posterior margins of thoracic somites with dorsal serration and sensilla arising from small socles; P2-P5-bearing somites additionally with 1 tube pore centrally. Last thoracic and first abdominal somites fused to form genital double somite, juncture detectable by dorsal serration. Abdominal part of GDS with serrated posterior margin and pair of tube pores; second and third abdominal somites dorsally serrated on posterior margins, second somite with fine, third somite with stronger spikes. Penultimate somite without sensilla or tube pores. Telson slightly smaller than preceding somite, FR widely separated proximally. Anal operculum basally with pair of sensilla and moderate spinules at apical margin.

FurCAL RAMI (Fig. 12A-B). Slender, about 5 times longer than broadest part, proximally with tube pore, and with 7 setae: I and II central on outer margin, II slightly longer than I; III subapical on dorsal side; 


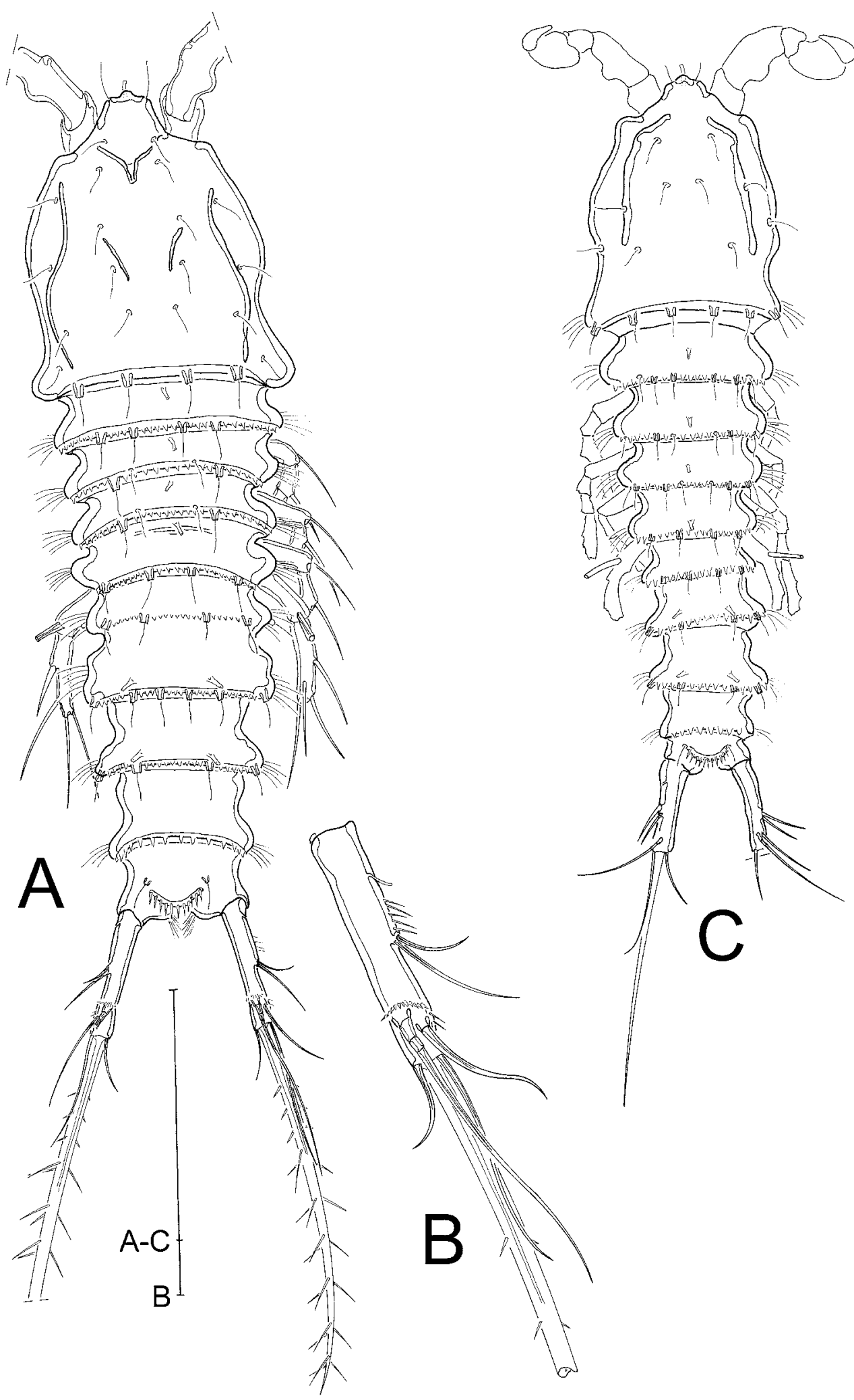

Fig. 12. Laophontodes gertraudae sp. nov., paratypes. A-B. $q$ (SMF 37117/1). A. Habitus, dorsal view. B. Right furcal ramus, dorsal view. C. $\widehat{\partial}$ (SMF 37118/1). Habitus, dorsal view. Scale bar: A, $\mathrm{C}=100 \mu \mathrm{m}, \mathrm{B}=50 \mu \mathrm{m}$. 




Fig. 13. Laophontodes gertraudae sp. nov., ㅇ. A. A1 and R (paratype SMF 37119/1). A'. Detail of third segment of A1 (holotype, SMF 37114/1), asterisks (*) indicate corresponding setae. B. A2 (holotype, SMF 37114/1), dotted circle indicates position of exopodal seta. B'. A2 allobasis (holotype, SMF 37114/1), drawn from counterpart. B”. A2 enp (paratype SMF 37117/1). C. GF with P6 (holotype, SMF $37114 / 1)$. Scale bar $=50 \mu \mathrm{m}$. 
IV and V apical, IV very narrow and less than half length of V, V tripinnate; VI apical on inner margin, as long as II; VII dorsal, tri-articulated at base, on pedestal surrounded at base by ring of spinules.

ANTENNULE (Fig. 13A-A'). 5-segmented. First segment with 1 bipinnate apical seta, and annular row of long spinules; second segment twice as long as first, medially with spinulose 'bump' on posterior margin, distally with 9 bare setae; third segment as long as second, with 7 bare setae and 1 aes; fourth segment smallest, partially overlapped by preceding segment (Fig. 13A'), with 1 bare seta; fifth segment (Fig. 13A) with 9 bare setae and apical trithek formed by 1 small aes and 2 bare setae.

SETAL FORMULA. 1-1/2-9/3-7+aes/4-1/5-10+aes.

Antenna (Fig. 13B, B', B"). With allobasis. Coxa small, triangular; allobasis with abexopodal row of spinules and 1 bare seta; exp (Fig. 13B") represented by small bare seta; enp (Fig. 13B-B') covered with several spinules, outer apical margin with spinulose frill, inner margin with 2 bare spines and 1 slender bare seta, plus 5 apical elements, 3 of which geniculate.

MD, MXL, MX AND MXP. Described from male.

Swimming LeGs. P1 (Fig. 14A) with lengthwise elongated coxa; basis as long as coxa, with 1 bipinnate outer seta and 1 uniplumose seta displaced to anterior surface. Enp 2-segmented, enp-1 strong and elongated, with row of spinules on outer and inner margins; enp- 2 small, less than $1 / 3$ length of enp-1, apically with claw and 1 slender geniculate bare seta, and subapically with small bare seta. Exp 3-segmented, half the length of enp-1. Exp-1 with 2 spinules and uniplumose spine on outer margin; exp-2 with outer row of spinules and 1 long bare geniculate outer seta; exp-3 with 4 long bare geniculate setae. P2-P4 (Fig. 14BD) with transversely elongated bases, 3-segmented exopods and 2-segmented endopods. All exopodal segments with row of spinules on outer margin, exp-1 and exp-2 additionally with fine spinules sparsely on inner margin; exopods without inner setae; exps-1 and 2 with bipinnate outer spine; exp-3 longest, with 3 bipinnate outer spines, and apically with 1 bipinnate outer seta and 1 biplumose inner seta. P2P4 enp-1 small, without spinules and setae; enp-2 elongate, spinulose, with 2 biplumose apical setae. P5 (Fig. 14E) benp represented by 2 setae, one biplumose and one of fish-bone aspect; tube pores not discernible. Outer apical margin with setophore accompanied by long spinules and carrying 1 bare seta. Exp fused to benp, slender, carrying 2 outer, 1 subapical and 2 apical setae, all but one bipinnate.

Genital FIELD (Fig. 13C). With single gonopore; P6 strongly reduced, limbs fused, with a small bare spine on each side.

\section{Male}

The male differs from the female in the following characters: body size, A1, P3 endopod, P5, no GDS. The mouthparts are of same shape as in the female.

HaBITus (Fig. 12C). As in female, but smaller (body length from rostral tip to end of FR: 276-312 $\mu \mathrm{m}$ $(\mathrm{n}=3)$ and narrower.

Antennule (Fig. 15A-A'). 6-segmented, chirocer. First segment as in female apically with 1 bipinnate seta and annular row of long spinules; second segment medially with spinulose 'bump' on posterior margin and 8 bare setae; third segment with 4 bare setae; fourth segment (Fig. 15A') minute, almost completely surrounded by segments 3 and 5, with 1 bare seta; fifth segment (Fig. 15A-A') swollen, antero-ventrally with 9 bare setae and 1 strongly sclerotized bare spine, additionally with aes and accompanying seta arising together from pedestal; sixth segment tapering distally, with 9 bare setae, and small aes and 2 bare setae forming trithek. 


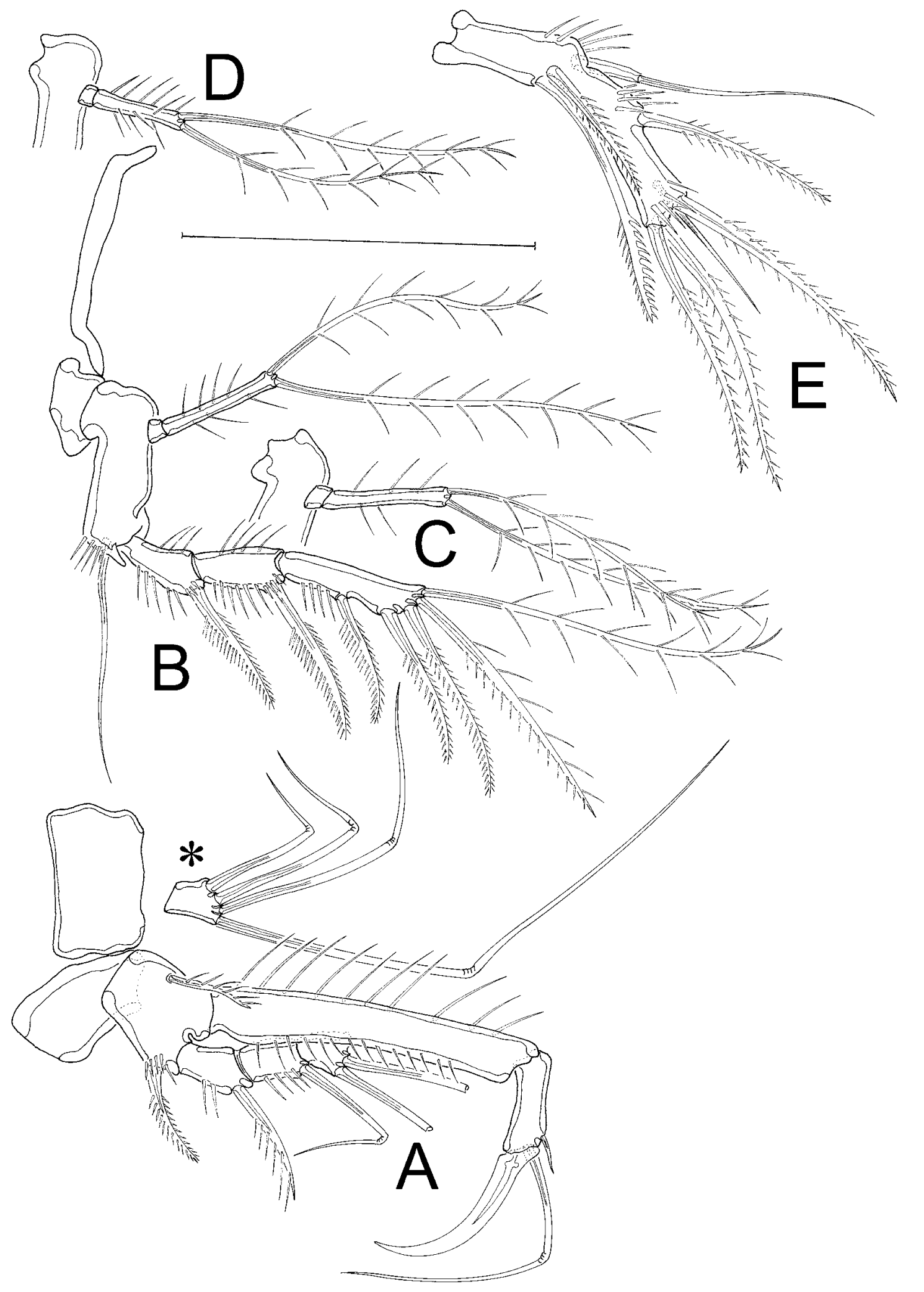

Fig. 14. Laophontodes gertraudae sp. nov., paratype, $q$ (SMF 37119/1). A. P1, asterisk (*) indicates exp-3 of counterpart. B. P2. C. P3 enp. D. P4 enp. E. P5. Scale bar $=50 \mu \mathrm{m}$. 


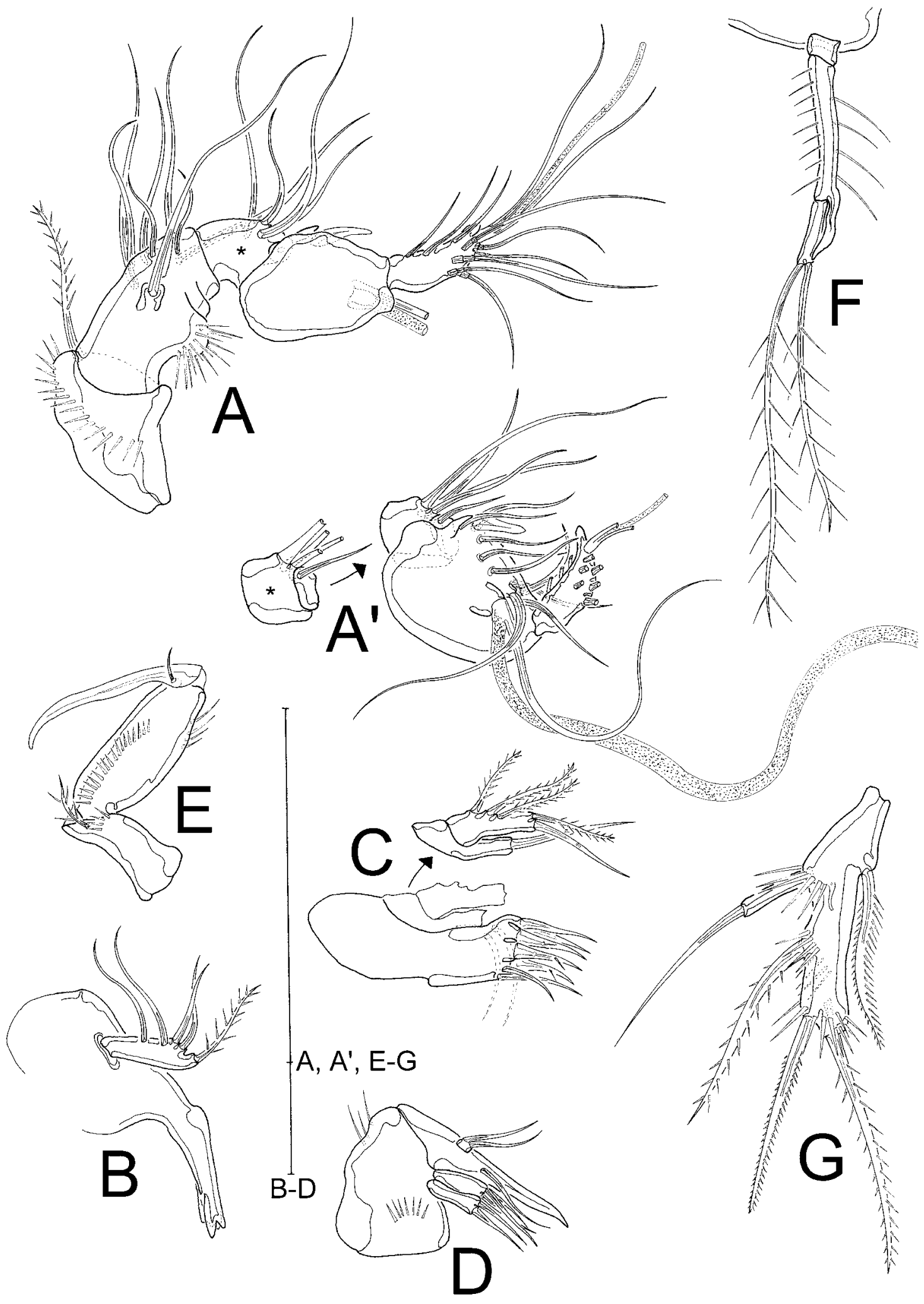

Fig. 15. Laophontodes gertraudae sp. nov., allotype, $\widehat{\jmath}$ (SMF 37115/1-9). A. A1. A'. Segments 3, 4, 5 and 6 of A1, drawn from counterpart (fourth segment marked with asterisk *). B. Md. C. Mxl. D. Mx. E. Mxp. F. P3 enp. G. P5. Scale bar $=50 \mu \mathrm{m}$. 
SETAL FORMULA. 1-1/2-8/3-4/4-1/5-11+aes/6-11+aes.

MandiBLe (Fig. 15B). With slender gnathobase bearing 5 teeth; md palp 1-segmented, with 4 lateral setae and 1 terminal bipinnate seta.

MaXillule (Fig. 15C). Praecoxal arthrite with 5 strong bare spines, 2 subapical setae and 2 surface setae. Coxa without spinules, terminally with 1 bare seta. Basis without spinules, terminally with 1 bare and 1 bipinnate seta, laterally with 1 bipinnate seta between basal endite and enp. Exp and enp each represented by 1 bipinnate seta.

MaXiLla (Fig. 15D). Syncoxa bearing 2 rows of spinules and 2 endites. Proximal and distal endites with 2 and 3 bare setae, respectively. Basis distinct, produced into strong claw, with 1 seta. Enp 1-segmented and small, with 2 bare setae.

MAXILLIPED (Fig. 15E). Syncoxa apically with scant spinules and 1 biplumose seta; basis longer than syncoxa, with row of spinules on anterior surface and long spinules on posterior margin; enp formed into long bare claw reaching length of basis, with minute bare basal seta.

Swimming Legs. P3 (Fig. 15F) exp as in female. Enp 3-segmented; enp-1 minute and unarmed; enp-2 longest, with row of spinules on both inner and outer margin, without setal elements but with apophysis on inner apical margin, reaching almost the length of enp-3; enp-3 half as long as enp-2, with 2 biplumose apical setae. P5 (Fig. 15G) benp small with 1 outer seta arising from elongated setophore that is surrounded by long spinules at base with 1 tube pore; endopodal part of benp virtually absent, represented by 1 bipinnate seta reaching length of exp. Exp fused to benp, with 1 outer, 1 subapical, and 1 apical seta, all bipinnate.

Laophontodes monsmaris sp. nov. urn:1sid:zoobank.org:act:CCE6A44F-6FBC-4F32-A18D-33244AA07160

Figs 16-20

\section{Etymology}

The specific epithet is derived from the Latin 'mons' (mount) and 'maris' (from the sea), in reference to the seamount type locality.

\section{Type material}

The specimens were originally assigned to Laophontodes typicus by George \& Schminke (2002).

\section{Holotype}

ATLANTIC OCEAN: $\hat{O}$, upper slope of the north eastern plateau of the Great Meteor Seamount, $30^{\circ} 05.9^{\prime} \mathrm{N}, 28^{\circ} 24.3^{\prime} \mathrm{W}$, station \#521, depth $422 \mathrm{~m}$, research cruise M42/3 of German RV METEOR (1998), 14 Sep. 1998, Dr Nils Brenke leg. (SMF 37120/1-2, on 2 slides).

\footnotetext{
Allotype

ATLANTIC OCEAN: , same locality as for holotype (SMF 37121/1, on 1 slide).

\section{Paratypes}

ATLANTIC OCEAN: 5 $ð$, same locality as for holotype (SMF 37123/1, SMF 37124/1, SMF 37125/1, SMF 37126/1, SMF 37127/1; on 5 slides); 1 , , upper slope of the Great Meteor Seamount $30^{\circ} 06.0^{\prime} \mathrm{N}$, $28^{\circ} 24.3^{\prime} \mathrm{W}$, station \#520, depth $511 \mathrm{~m}$, research cruise M42/3 of German RV METEOR (1998) (SMF 37122/1, on 1 slide); copepodid CV, same locality as for holotype (SMF 37128/1, on 1 slide); copepodid CV, same locality as for holotype (SMF 37129/1, on 1 slide).
} 


\section{Description}

\section{Female}

Habitus (Fig. 16A). Cylindrical, body length ( $\mathrm{R}$ to end of FR) 305-317 $\mu \mathrm{m}(\mathrm{n}=2)$. Cphth slightly longer than broad, $1 / 3$ of total body length, posteriorly slightly bulged laterally; dorsally, 2 cuticular longitudinal ridges run towards but do not reach posterior margin. $\mathrm{R}$ small, fused to cphth, with 2 sensilla and 1 tube pore on apical margin. Body somites clearly distinct. Last thoracic and first abdominal somite fused to form GDS, juncture detectable by dorsal serration. Posterior margin of body somites, except penultimate somite, with row of fine setules; cphth, thoracic somites (except P5-bearing somite) and abdominal part of GDS with 1 pair of sensilla arising from small cuticular socles. First 3 free thoracic somites and abdominal part of GDS additionally with tooth-like cuticular projections, remaining somites dorsally serrated on posterior margin. P2-P5-bearing somites and thoracic part of GDS additionally with 1 tube pore centrally. Thoracic and Abdominal subunits of GDS with pair of tube pores; abdominal subunit additionally with serrated posterior margin. Second and third abdominal somites also with paired tube pores. Penultimate somite without sensilla or tube pores. Telson slightly smaller than preceding somite and mostly overlapped by it, with FR widely separated proximally. Anal operculum with pair of sensilla and with spinulose apical margin.

FurCaL RAMI (Fig. 16A-B). Slender, about 5 times longer than its broadest part, proximally with tube pore, and with 7 setae: I and II central on outer margin, II twice as long as I; III subapical on outer margin; IV and V apical, IV half of the length of V; VI apical on inner margin, slightly longer than III; VII dorsal, arising from pedestal, tri-articulated at base.

Antennule (Fig. 17A). 5-segmented. First segment with 1 bipinnate seta and some spinules apically; second segment without 'bump' on posterior margin, corresponding area covered with long spinules, distally with 9 bare setae; third segment as long as previous segments, with 7 bare setae and 1 aes; fourth segment smallest, partially overlapped by third segment, with 1 bare seta; fifth segment with 9 bare setae and apical trithek formed by 1 small aes and 2 bare setae.

SETAL FORMULA. 1-1/2-9/3-7+aes/4-1/5-11+aes.

A2, Mxl AND Mx. Described from male.

MANDiBLE (Fig. 17B). Gnathobase bearing 5 teeth; palp 1-segmented, with 5 bare setae.

MAXILLIPED (Fig. 17E). Very large (cf. Fig. 16C); syncoxa cylindrical, without spinules or setal elements; basis longer than syncoxa, also lacking ornamentation; enp produced into long, slender claw and accompanied by 1 minute seta at its base.

Swimming Legs. P1 (Fig. 18A) coxa elongate; basis as long as coxa, with 1 bipinnate outer and inner seta, the latter displaced to anterior surface. Enp 2-segmented, enp-1 strong and elongate, with row of spinules on outer and the inner margins, inner spinules 2-3 times longer than outer spinules; enp- 2 small, less than $1 / 3$ length of enp-1, apically with 1 claw, 1 slender geniculate bare seta and 1 small subapical seta. Exp 3-segmented, less than $1 / 2$ length of enp-1. Exp-1 with scant spinules and 1 uniplumose spine on outer margin; exp-2 with outer and inner spinules and 1 long bare geniculate outer seta; exp-3 with some outer spinules and 4 long bare geniculate setae. P2-P4 (Figs 18B, 19A-B) with transversely elongated bases, 3-segmented exopods and 2-segmented endopods. All exopodal segments with a row of spinules on outer margin, exp-1 and exp-2 additionally with fine spinules sparsely on inner margins and 1 bipinnate outer spine; exp-1 without, exp- 2 with 1 inner seta; exp-3 longest segment, with 3 bipinnate outer spines and 2 bipinnate apical setae, additionally P2 exp-3 (Fig. 18B) with 1 inner seta, P3 and P4 exp-3 (Fig. 19B) with 2 inner setae. P2-P4 enp-1 small, without setae. Enp-2 elongated, with inner and 


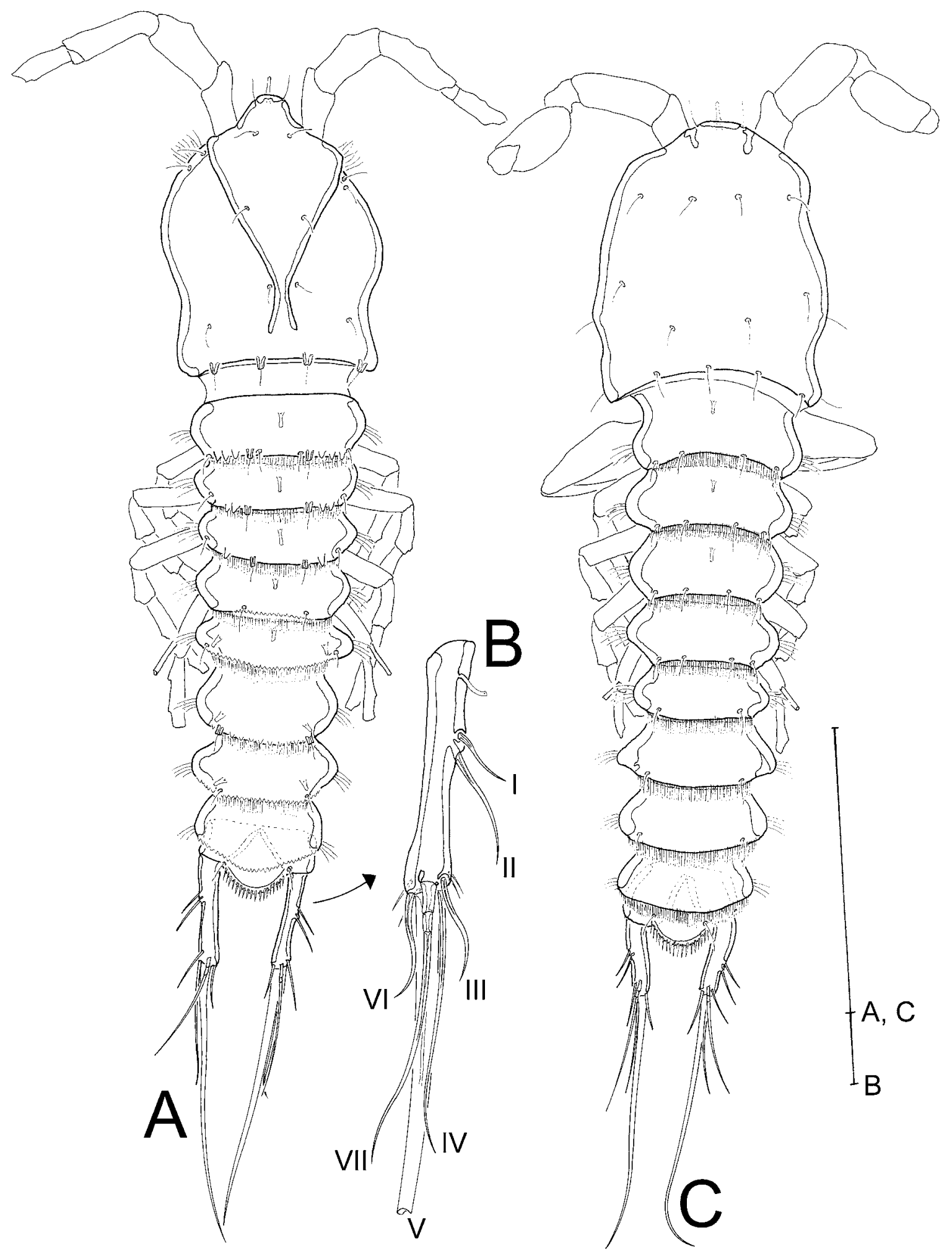

Fig. 16. Laophontodes monsmaris sp. nov. A-B. Allotype, $q$ (SMF 37121/1). A. Habitus, dorsal view. B. Right furcal ramus, dorsal view. C. Holotype, $\widehat{\jmath}$ (SMF 37120/1-2), habitus. Scales: A, C $=100 \mu \mathrm{m}$, $\mathrm{B}=50 \mu \mathrm{m}$. 


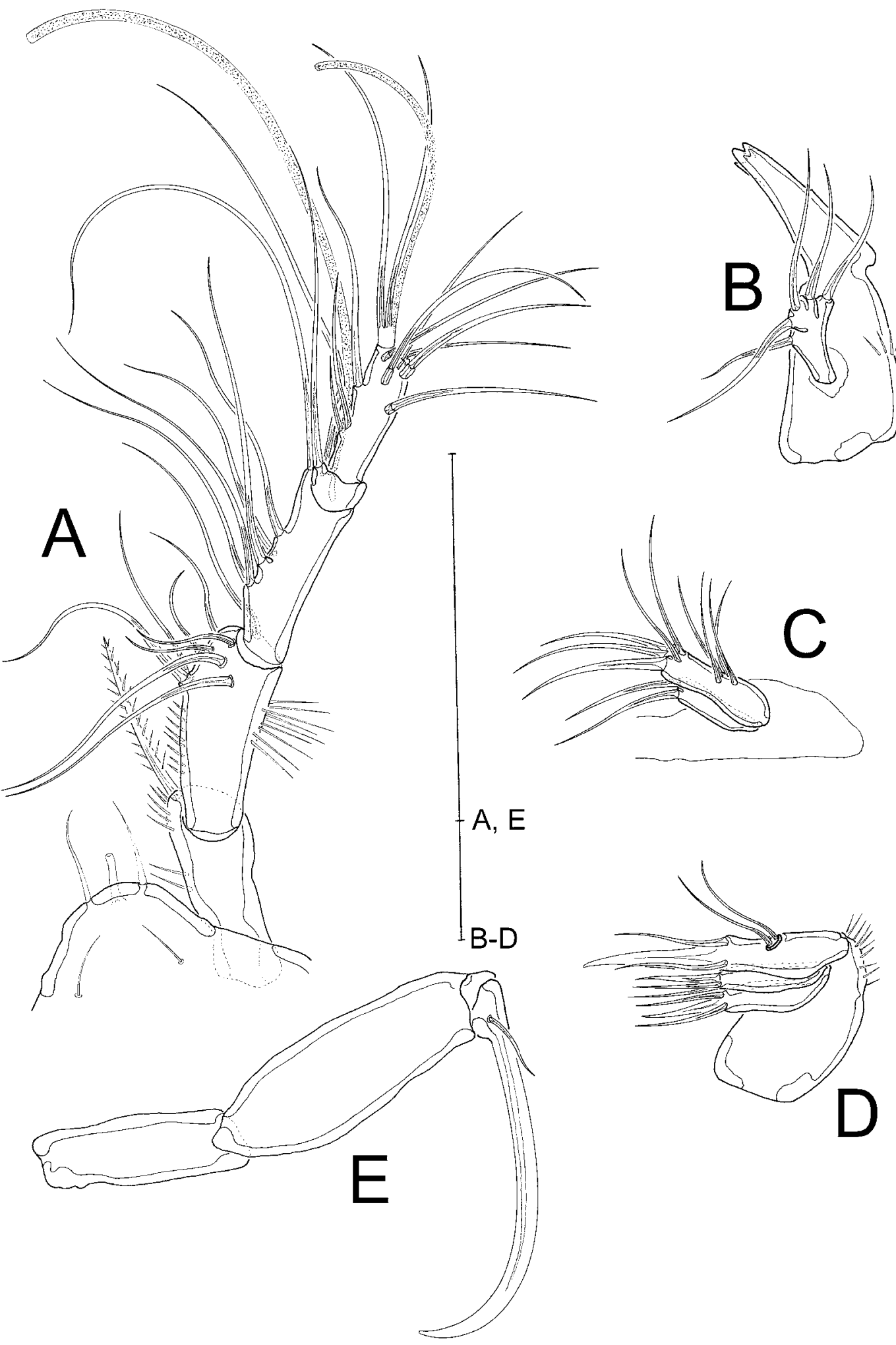

Fig. 17. Laophontodes monsmaris sp. nov. A-B, E. Allotype, $q$ (SMF 37121/1). A. A1 and R. B. Md. C. Holotype, đ̊ (SMF 37120/1-2). Mxl coxa and basis. D. Paratype, ô (SMF 37121/1). Mx. E. Mxp. Scale bar $=50 \mu \mathrm{m}$. 
outer spinules and 2 biplumose apical setae in P2 and P3 (Figs 18B, 19A) and 1 additional bare seta in P4 (Fig. 19B). P5 (Fig. 18C) benp reduced to 2 setae, one bipinnate and one apically biplumose; tube pores not discernible. Setophore on outer apical margin accompanied by long spinules and 1 tube pore and carrying 1 bare seta. Exp fused to benp, slender, carrying 3 outer seta, one of which bipinnate, the others bare, and 2 apical bipinnate setae; additionally with small tube pore and spinules subapically.

GENITAL FIELD. Not drawn, almost identical to that in Laophontodes sarsi sp. nov.

\section{Male}

The male differs remarkably from the female in terms of body ornamentation and missing GDS. Further differences can be observed in A1, P3 and P4 endopods, and P5. Note that the A2, mxl, and mx are described from the male being obscured/damaged in the female.

Habitus (Fig. 16C). Same length as female (body length, R-FR: 300-317 $\mu \mathrm{m} ; \mathrm{n}=3$ ). Cephalothoracic longitudinal cuticular ridges absent, as are the sensillar socles, serrated posterior margins, and toothlike cuticular projections on the body somites. As in female fine setules on posterior margins of body somites, and additionally on penultimate body somite. As in female T mostly overlapped by the previous abdominal somite. FR slightly smaller and more compact relative to female.

Antennule (Fig. 20A-A'). 6-segmented, chirocer. First segment as in female apically with 1 bipinnate seta and scant spinules; second segment without 'bump' or corresponding long spinules, with 9 bare setae; third segment with 7 bare setae; fourth segment minute, with 2 bare setae; fifth segment swollen, with 10 bare setae plus 1 strongly sclerotized bare spine, additionally with 1 aes and 1 accompanying seta arising together from pedestal; sixth segment bent and tapering distally, with 8 bare setae, and 1 small aes and 2 bare setae forming trithek.

SetAL FORMULA. 1-1/2-9/3-7/4-2/5-12+aes/6-10+aes.

AnTENNA (Fig. 20B). Allobasis with 1 bare abexopodal seta and scant spinules; exp represented by small bare seta; enp slightly smaller than allobasis, anteriorly with row of spinules, 2 bipinnate distal setae and 2 bare and 3 geniculated apical setae, outermost apical seta accompanied by minute tube pore, additionally with cuticular dentate frill.

MAXILlule (Fig. 17C). Praecoxal arthrite not described. Coxa unarmed, apically with 2 bare setae; basis without spinules, terminally with 3 bare setae, laterally with 1 bipinnate seta between basal endite and enp. Exp represented by 2, enp represented by 3 bare setae.

Maxilla (Fig. 17D). Syncoxa bearing 1 row of spinules and 2 endites. Proximal and distal endites each with 3 bare setae. Basis distinct, produced into strong claw, with 2 bare setae. Enp 1-segmented, minute, with 2 bare setae.

SwIMmING LeGs. P3 (Fig. 19C) exp as in female; enp 3-segmented; enp-1 minute and unarmed; enp-2 longest, with row of spinules on inner and outer margins, without setal elements but with apical apophysis not reaching apical margin of enp-3; enp-3 $1 / 4$ length of enp-2, with 2 biplumose apical setae. P4 (Fig. 19D) exp as in female; enp 2-segmented; enp-1 minute and unarmed; enp-2 with row of spinules on inner and outer margins, 1 bare outer setae, 1 biplumose inner seta and 2 biplumose apical setae. P5 (Fig. 20C) benp small with 1 outer seta arising from elongated setophore; endopod virtually absent, represented by 1 bipinnate seta longer than exp. Exp fused to benp, with 1 outer bipinnate, 1 subapical bare, and 2 apical bipinnate setae. 


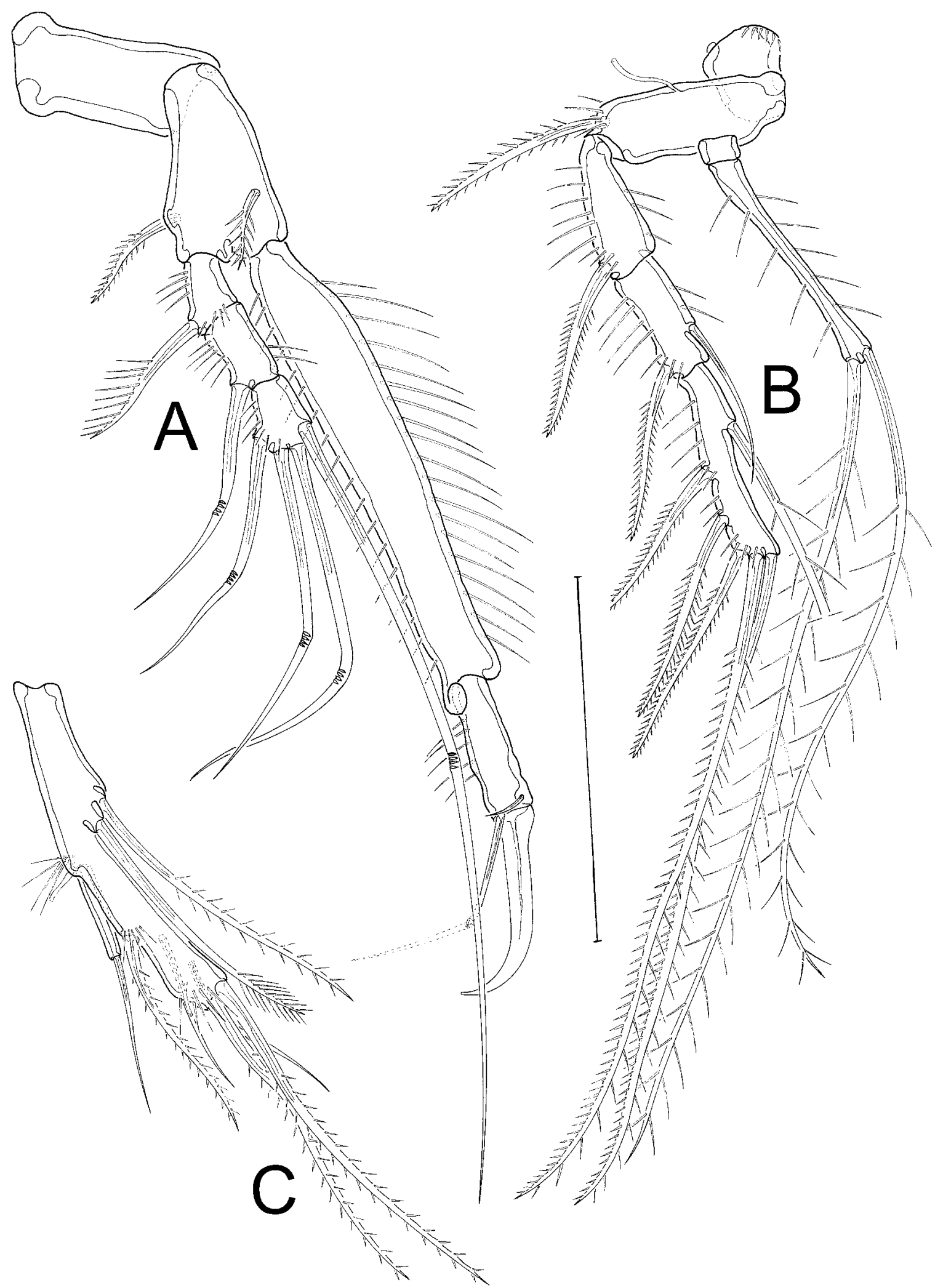

Fig. 18. Laophontodes monsmaris sp. nov., allotype,, (SMF 37121/1). A. P1. B. P2. C. P5. Scale $=50 \mu \mathrm{m}$. 


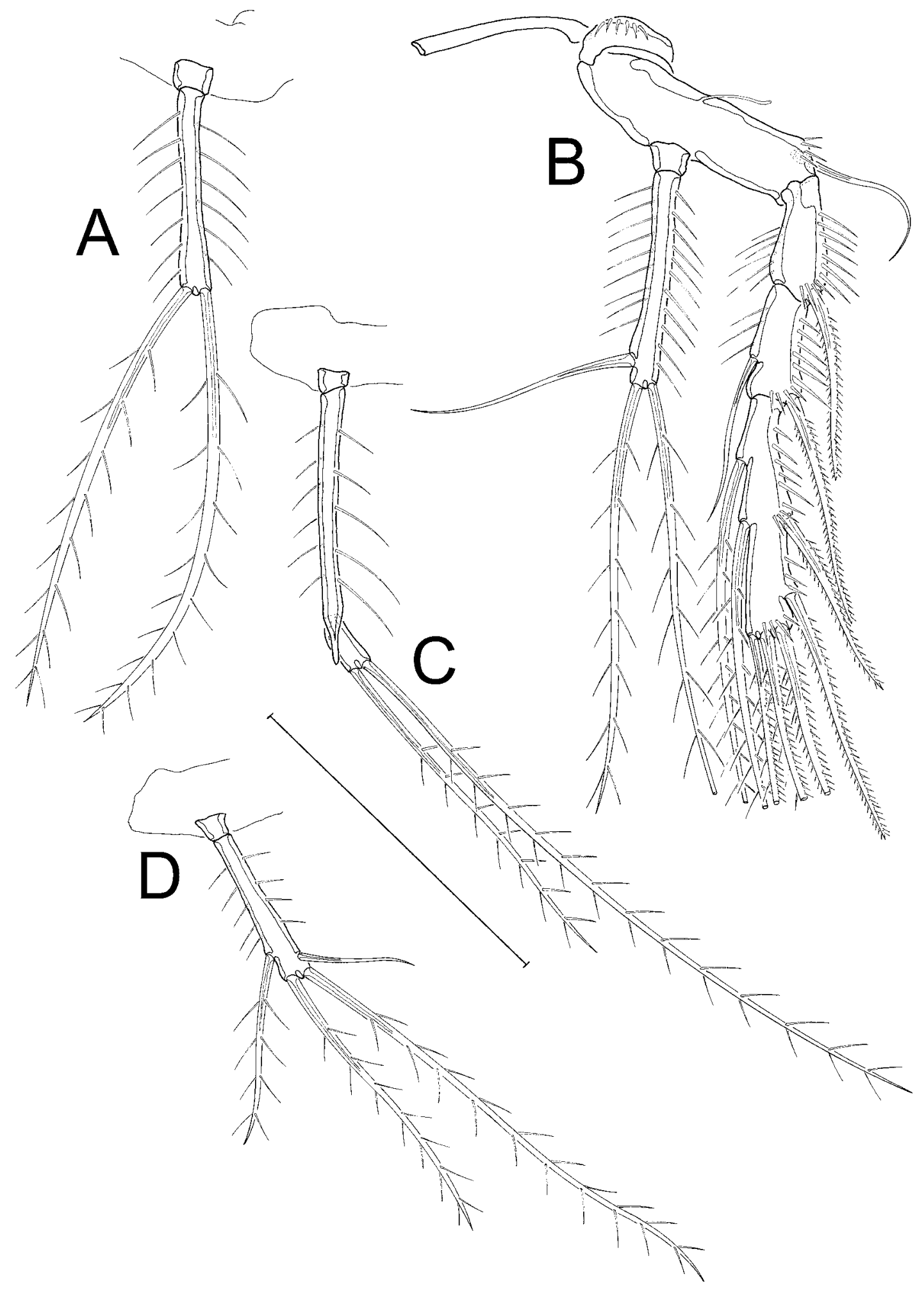

Fig. 19. Laophontodes monsmaris sp. nov. A. Paratype, + , (SMF 37122/1), P3 enp. B. Allotype, , (SMF 37121/1), P4. C. Paratype, đ̂, (SMF 37125/1), P3 enp. D. Paratype, ô, (SMF 37125/1), P4 enp. Scale $=50 \mu \mathrm{m}$. 

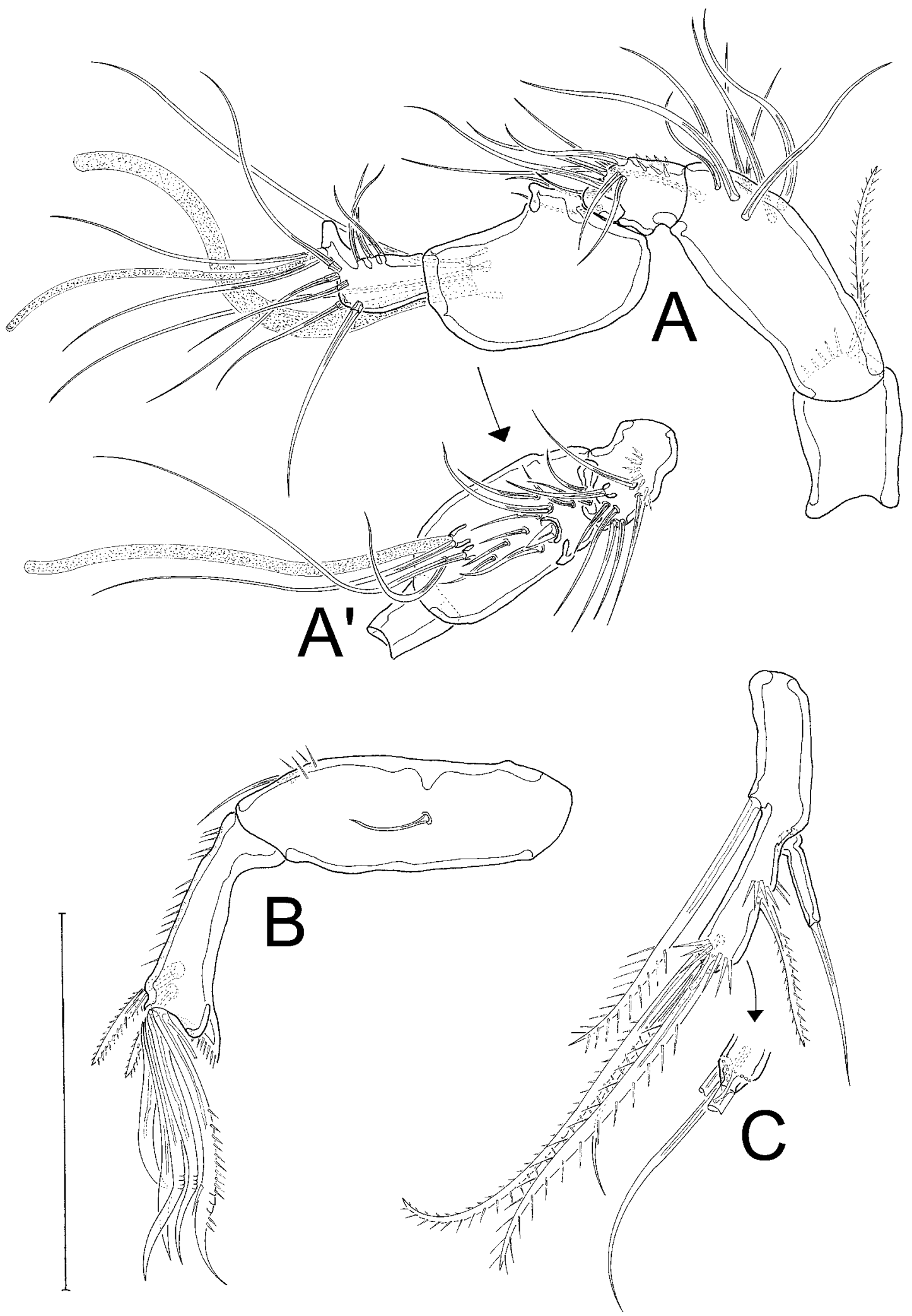

Fig. 20. Laophontodes monsmaris sp. nov., paratypes, $\widehat{\partial}$. A. A1 (SMF 37125/1). A'. Segments 3, 4, 5 and 6 (with edge cut off) of A1 (SMF 37125/1). B. A2 (SMF 37125/1). C. P5 (SMF 37123/1). Scale $=50 \mu \mathrm{m}$. 


\section{Laophontodes norvegicus sp. nov. \\ urn:1sid:zoobank.org:act:67160680-DF0F-4A80-9A4F-474ED95329F1}

Laophontodes typicus - Sars 1908: 270, pl. CLXXXVII (non T. Scott, 1894).

\section{Etymology}

The epitheton 'norvegicus' refers to the region where the species was first recorded (cf. Sars 1908).

Under examination for the present study, it transpires that the detailed description of Laophontodes typicus presented by Sars (1908) was in fact an account of a new species, proposed here as Laophontodes norvegicus sp. nov. A redescription to establish the new species was not possible here, as the original material is not available (Wilhelmsen, pers. comm.), and no additional material has been reported to date. Thus, a holotype specimen is not available; however, Sars' (1908) detailed description provides all species information. The type locality is the Norwegian coast, Sars (1908) having found specimens on the southern coast (Bukken) and in the northern Salten fjord.

\section{Discussion}

\section{Difficulties in characterizing Laophontodes typicus T. Scott, 1894}

Assignment of collected specimens to a species requires an unambiguous morphological characterization of that species. However, in the case of Laophontodes typicus this caused considerable difficulties. All individuals examined in the present contribution were previously assigned to L. typicus (George 1999, 2005; George \& Schminke 2002; Ventham 2011), as were other redescriptions (T. Scott 1894, 1907; Sars 1908; Lang 1948; Klie 1950; Chislenko 1967, 1977; Kornev \& Chertoprud 2008). This may reflect the rather unspectacular morphology of L. typicus, which in comparison with other Laophontodes species lacks dorsal and/or lateral processes, transformation or reduction of limbs or body somites and other distinctive morphological characteristics. It is, furthermore, compounded by the incomplete and imprecise description by T. Scott (1894) and similarly unsatisfactory redescriptions (e.g., Klie 1950; Chislenko 1967, 1977). Consequently, it was generally accepted that L. typicus, whilst sharing all characters of the genus (cf. George \& Gheerardyn 2015), does not exhibit discrete apomorphies that would enable unambiguous differentiation from other species of Laophontodes. It was furthermore accepted that L. typicus presented a high intraspecific variability, including body shape and its ornamentation, reduction of setae/spines and even in the reduction or fusion of the swimming leg segments. Considering that these characters are all commonly scrutinized when discriminating between harpacticoid species, it is sobering that such a high variability was not questioned earlier.

The absence of type material for L. typicus (Lowe, pers. comm.) has further compounded difficulties in providing an unequivocal characterization for this species. Similarly, some of the new species presented in this paper are not exhaustively described owing to a lack of material. It is now widely believed that molecular studies are the best method to determine whether observed morphological differences result from intraspecific variability or the existence of a species complex (e.g., Easton et al. 2010). However, in this case, as in many others, molecular analyses were impracticable owing to the absence of material, its age, value or storage method (formaldehyde for years or even decades). Nevertheless, it still holds that "for Harpacticoida the adult morphology offers the broadest database available for comparative analysis" (Willen 2000: 3) and for Laophontodes typicus a morphological approach remained the only option.

All available literature and data from the material studied by the present author was combined to enable the best possible morphological comparison. However, owing to the incomplete description of many characters, a phylogenetic approach was largely discarded in favour of a diagnostic-typological 
one. Only four of the treated species (Laophontodes scottorum sp. nov., L. gertraudae sp. nov., L. monsmaris sp. nov., L. norvegicus sp. nov.) can be characterized by clear apomorphies. The remaining species (L. typicus, L. sarsi sp. nov.), descriptions (T. Scott 1894; Klie 1950; Chislenko 1967, 1977), and determinations (Lang 1948; Wells 2007; Kornev \& Chertoprud 2008) were based on typological features only.

The following discussion omits the contributions of Chislenko (1977) and Kornev \& Chertoprud (2008); the former author only described the female P5 which does not provide enough information to be included in the present analysis, whilst the latter appeared to have made an erroneous determination: the P2-P4 exp-3 is described as bearing 2 instead of 3 outer spines; the presence of only 2 outer spines shows a derived state not recorded in Laophontodes or even Laophontodinae (e.g., Lang 1948; George \& Gheerardyn 2015).

\section{Useful characters for species discrimination}

The main problem that arose during this study was the uneven absence of characters across the redescriptions, both because they were not considered or were overlooked when the specimens were originally examined, and because material is no longer available. Characters that could not be examined across all species included the antennary exopod, the endopodal seta on mxp, the endopodal tiny seta on P1 enp-2, and the number of basoendopodal setae on the female P5 (Table 2, characters I-IV). This left 22 characters that could be used for the present study (Table 2, characters 1-22).

\section{Definition of Laophontodes typicus T. Scott, 1894 and assignment of the Sussex material to that species}

It is the author's opinion that the original description of T. Scott (1894) must be retained for L. typicus. Despite its incompleteness and partial imprecision, it does provide unequivocal characters. In addition to the generic characters, as updated by George \& Gheerardyn (2015), three characters are only present in the material described by T. Scott (1894), Klie (1950) and in the Sussex material (Fig. 1C, Table 2), these are:

Character 1. P2 exp-3 with 1 inner seta arising proximally;

Character 2. P3 exp-3 with 1 inner seta arising proximally;

Character 3. P4 exp-3 with 1 inner seta arising proximally.

These characters are absent from the remaining species, with the exception of $L$. monsmaris sp. nov. (Table 2). Laophontodes monsmaris sp. nov. shares character 1 (Fig. 18B), but presents an even more plesiomorphic state in P3 and P4, carrying 2 inner setae on each exp-3 (Fig. 19B; Table 2: characters 21-22).

Examination of the material from the coast of Sussex for the present contribution confirms it should be assigned to Laophontodes typicus, although comparison of all characters was not possible. Klie (1950) explicitly confirmed the presence of characters 1-3 in his material from the Bight of Kiel, Germany, when pointing to the difference with the redescription by Sars (1908). Regarding the geographical distribution, L. typicus seems to be restricted to the North Sea and the Baltic Sea (Fig. 1A-D), not extending to the Atlantic Ocean or European Arctic as previously assumed. Reports from other authors (France: e.g., Jakubisiak 1933, 1936; Sweden: Lang 1948; Ireland: Roe 1958) cannot be validated owing to the absence of material.

\section{Establishment of Laophontodes scottorum sp. nov.}

The 'cotype' and T. Scott's (1907) redescription of L. typicus present a series of exclusive characters: 


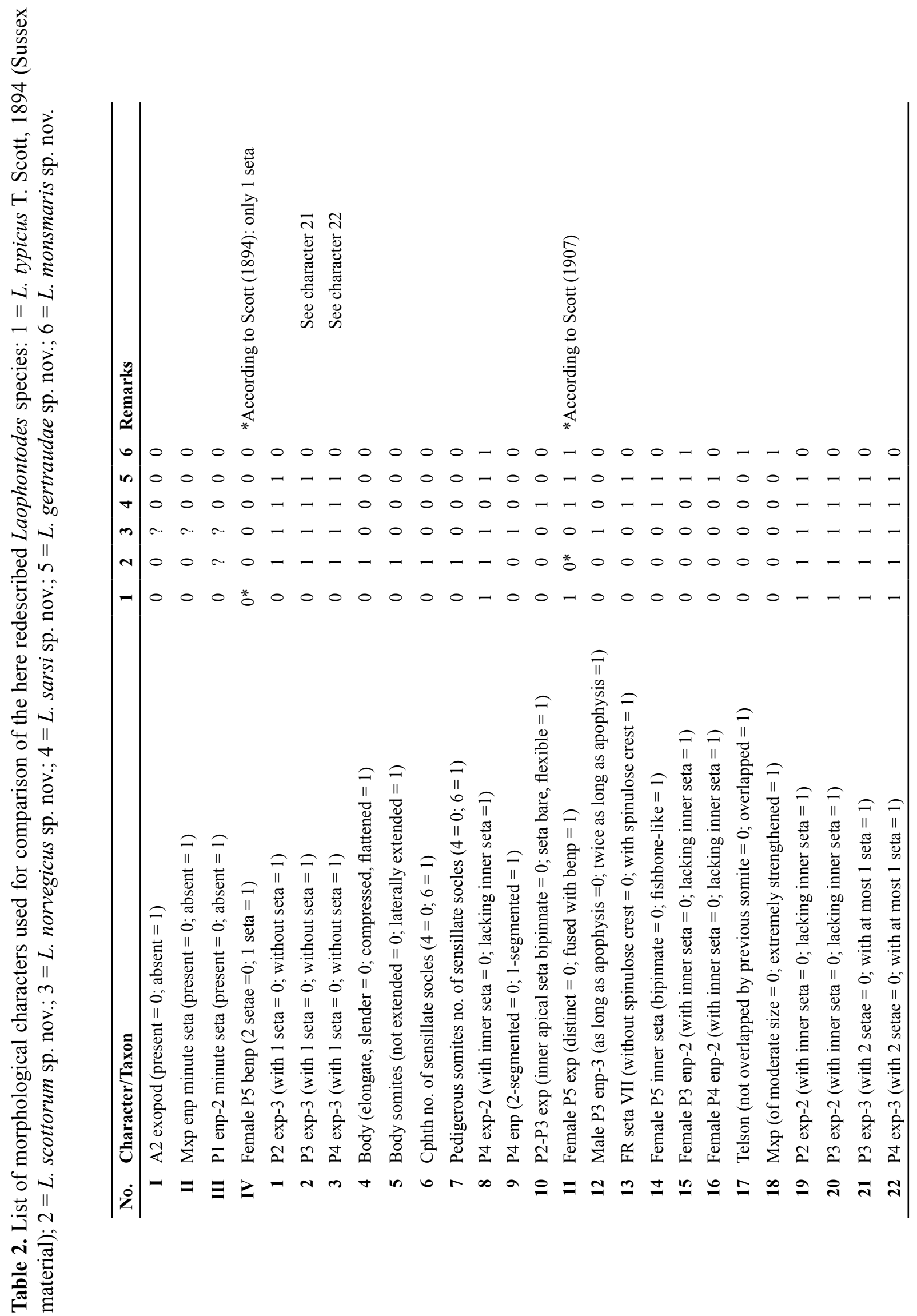


Character 4 Body comparatively compressed and dorsoventrally flattened;

Character 5 Body somites laterally extended;

Character 6 Number of sensillate socles on cphth increased (6 instead of 4);

Character 7 Number of sensillate socles on P2-P5-bearing somites increased (6 instead of 4).

When compared to certain other Harpacticoida (e.g., Peltidiidae, Porcellidiidae), L. scottorum presents an elongated body, but it also shows a unique compression and dorsoventral depression (Fig. 7A) in comparison with other Laophontodes species (character 4). This is emphasized by the lateral elongation of the body somites (character 5). The resultant broadening of the body is accompanied by an increase in the number of sensilla-bearing socles on the posterior margins of both the cphth (character 6) and the P2-P5-bearing thoracic somites (Character 7). The four characters listed above are interpreted as apomorphies of the species. Character 6 also occurs in Laophontodes sarsi sp. nov., but this species lacks characters $4-5$, and 7 , and character 6 is, therefore, assumed to have evolved convergently in both taxa.

The presence of derived characters $4-7$, in combination with the absence of characters $1-3$, proves that neither the 'cotype' nor the specimens of T. Scott (1907) can be allocated to L. typicus. It is concluded that T. Scott (1907) described a new species, but erroneously assigned it to L. typicus: The assignment of the 'cotype' to that new species is unproblematic. The new species is established as Laophontodes scottorum sp. nov., with the 'cotype' designated as the holotype. The currently known geographical distribution of L. scottorum sp. nov. is the western and eastern coast of Scotland (Fig. 1A-B).

\section{Establishment of Laophontodes norvegicus sp. nov. and $\boldsymbol{L}$. sarsi sp. nov.}

G.O. Sars was a keen observer, and his species descriptions are mostly detailed and distinguished. This may explain why Lang (1948) and subsequent authors focus on his redescription of L. typicus (Sars 1908) rather than the work of T. Scott $(1894,1907)$. Sars' (1908) redescription was based on material collected from the Bukken and Salten fjords (southern and northern Norway, respectively; Fig. 1F). Additional material collected and determined as L. typicus by G.O. Sars, here described as Laophontodes sarsi sp. nov., also originates from Norway, from the Skjerstad fjord which is close to the Salten fjord (Fig. 1C). All the Norwegian material differs from the original description (T. Scott 1894), lacking characters 1-3 (Table 2), and it is concluded that they do not belong to Laophontodes typicus. Moreover, they do not exhibit characters 4-7 and, therefore, cannot be assigned to L. scottorum sp. nov. However, the specimens from the Skjerstad and Bukken/Salten fjords cannot be allocated to the same species either, as they also differ from each other in the following characters:

Character 8 The P4 exp-2 described by Sars (1908) on the material from the Bukken/Salten fjord lacks an inner seta (derived condition shared with L. typicus, L. scottorum sp. nov. and $L$. gertraudae sp. nov.), but one is present on the two females from Skjerstad (plesiomorphic condition shared with L. monsmaris sp. nov.) (Fig. 11C, Table 2);

Character 9 The illustration of the female P4 enp from the Bukken/Salten fjord appears to be 1-segmented, though this is not specified in the text: in the generic diagnosis Sars (1908: 269) described the P2-P4 enp as "much smaller than the outer [ramus], narrow linear in form, and composed of only two joints, the $1^{\text {st }}$ very small and in some cases imperfectly defined...". Subsequent authors (Lang 1948; Chislenko 1967; Wells 2007) mention a 1-segmented P4 enp. In contrast, the females from Skjerstad fjord clearly bear a 2-segmented P4 enp (Fig. 11C);

Character 10 The inner apical seta of P2 and P3 exp-3 on the material from the Bukken/Salten fjord is bipinnate (Sars 1908), but on the females from Skjerstad fjord it is bare and appears more flexible (Fig. 11A-B); 
Character 11 In the material from the Bukken/Salten fjord the female P5 exp is clearly described as distinct by Sars (1908), but an examination of the females from the Skjerstad fjord found it to be fused (Fig. 10D).

Further morphological differences regarding the A2 exp (Table 2, character I), the syncoxal seta on mxp, the minute seta on the maxillipedal claw (Table 2, character II) and the small seta on P1 enp-2 (Table 2, character III), cannot yet be considered: according to Sars (1908), these are missing in the specimens from the Bukken/Salten fjord, but clearly present in the females from the Skjerstad fjord (Fig. 10A$\mathrm{C}$, respectively). Without being able to study the material from the Bukken/Salten fjord, it remains uncertain whether Sars (1908) overlooked these characters (see above), or whether they are absent in these individuals. Nevertheless, characters 8-11 alone enable the differentiation of two Norwegian species. Furthermore, the specimens from the Bukken/Salten fjord present two derived characters: reduction of female P4 enp-1 to a 1-segmented P4 enp (character 9), and

Character 12 Male P3 enp-3 twice as long as the apophysis (cf. Sars 1908).

Lang (1948), Chislenko (1967) and Wells (2007) also documented a 1-segmented P4 enp (character 9), contradicting the original description of T. Scott (1894). However, both Lang (1948) and Wells (2007) based their statements on literature data (Lang (1948) did not provide a description of his own Gullmarfjord material), while Chislenko (1967) gave only a superficial description which leaves some doubt regarding its accuracy. In contrast, the description of Sars (1908) is comparatively precise and detailed and therefore, a 1-segmented P4 enp is considered to be a derived character for the material from the Bukken/Salten fjord.

It is not possible to compare the male P3 enp-3 (character 12) of material from the Bukken/Salten fjord with that from Skjerstad, as no males were collected at the latter site. However, examination of the remaining male specimens examined for this study and data available from literature (T. Scott 1907; Lang 1934; Schizas \& Shirley 1994; Arroyo et al. 2003; Kornev \& Chertoprud 2008; George \& Gheerardyn 2015) found that only two further species of Laophontodes present a P3 enp-3 extending the length of the apophysis, namely L. mourois Arroyo, George, Benito \& Maldonado, 2003 and $L$. spongiosus Schizas \& Shirley, 1994. These species differ remarkably from each other and from the material from the Bukken/Salten fjord, which, combined with derived characters 9 and 12, justifies the assignment of the material from the Bukken/Salten fjord to a new species, named here as Laophontodes norvegicus sp. nov. So far, it has been reported from the Norwegian coast only (Sars 1908) (Fig. 1E-F).

The females from Skjerstad are also clearly distinguished from the remaining specimens studied here. They differ from L. norvegicus sp. nov. by characters 8-11 as discussed above. Character 8 , the presence of an inner seta on P4 exp-2, however, is a (plesiomorphic) state also retained in L. monsmaris sp. nov. from the Great Meteor Seamount (Table 2). Nevertheless, the females from Skjerstad also differ from L. monsmaris sp. nov. due to the latter's unique apomorphic characters (see below). Chislenko (1967) similarly described an inner seta on P4 exp-2 from his material, but that author also described a 1-segmented P4 enp (see above) and a distinct P5 exp, which differ from the females from Skjerstad. The fact that, that the females from Skjerstad present character 8 uniquely in combination with character 10 (a bare and flexible inner apical seta on P2 and P3 exp-3, which is considered apomorphic for the females from Skjerstad), justifies the establishment of a new species, Laophontodes sarsi sp. nov. It is currently known from the Skjerstad fjord in northern Norway only (Fig. 1G). 


\section{Establishment of Laophontodes gertraudae sp. nov.}

The Patagonian material strongly resembles Laophontodes typicus and the other species treated here with regard to the habitus and shape of the appendages. In particular, it shares two unusual characters with $L$. sarsi sp. nov.:

Character 13 A spinulose crest surrounding furcal seta VII (Fig. 12B). This is absent from the other specimens examined for this study and has not been documented in the literature;

Character 14 The female P5 benp bears an inner seta that is of a fish-bone aspect on its distal half (Fig. 14E), rather than the typical bipinnate setae seen on other specimens from other regions.

Nevertheless, the Patagonian specimens may be characterized by two derived characters:

Character 15 Female P3 enp-2 lacking the inner seta (Fig. 14C);

Character 16 Female P4 enp-2 lacking the inner seta (Fig. 14D);

Although character 15 occurs in the females from Great Meteor Seamount (Table 2), other morphological differences with the seamount material (see below) show the Patagonian material to be distinct. All remaining individuals examined here and those described in the published literature present an inner seta on $\mathrm{P} 3$ and $\mathrm{P} 4$ enp-2. Thus, characters 15 and 16 justify the establishment of a new species Laophontodes gertraudae sp. nov., currently reported from the Chilean Patagonian continental slope only (George 1999, 2005) (Fig. 1I).

\section{Establishment of Laophontodes monsmaris sp. nov.}

Laophontodes monsmaris sp. nov. shares the presence of 1 inner seta on P2 exp-3 (character 1, Fig. 18B) with L. typicus, the presence of 1 inner seta on P4 exp-2 (character 8, Fig. 19B) with L. sarsi sp. nov. and the derived reduction of an inner seta in female P3 enp-2 (character 15, Fig. 19A) with L. gertraudae sp. nov. (Table 2). Nevertheless, the individuals from the Great Meteor seamount may be characterized unambiguously, owing to two apomorphies which are unique within Laophontodes:

Character 17 The telson is almost completely overlapped by the previous somite (Fig. 16A, C); only the anal operculum and the bases of the FR obtrude. This condition has not been documented for other Laophontodes species; previous observations of other species have found the penultimate somite joined to the anterior margin of the telson;

Character 18 The mxp (Fig. 17E) is exceptionally strengthened. As indicated in the male (Fig. 16C), the mxp is very robust and elongated, protruding laterally even beyond the P2-P4 bases. This has not been documented for other species of Laophontodes.

Both derived characters undoubtedly justify the establishment of the new species Laophontodes monsmaris sp. nov., however, it can be additionally differentiated from the other species studied here by four further plesiomorphic characters:

Character 19 P2 exp-2 with inner seta (Fig. 18B);

Character $20 \quad$ P3 exp-2 with inner seta;

Character 21 P3 exp-3 with 2 inner setae (Fig. 19B);

Character $22 \quad$ P4 exp-3 with 2 inner setae.

Furthermore, L. monsmaris sp. nov. differs from the other studied species in the absence/secondary reduction of a 'bump' on the second antennular segment and the sexually dimorphic retention/secondary formation of an inner seta in the male P4 enp-2. Nevertheless, as an unambiguous interpretation of 
these features as apo- or plesiomorphic requires a careful comparison with other representatives of Laophontodinae - which would go beyond the present contribution - they are not considered here.

So far, L. monsmaris sp. nov. has been reported from the Great Meteor Seamount only (Fig. 1H).

\section{Summarizing conclusion}

Examination of specimens determined as Laophontodes typicus T. Scott, 1894, but collected from disparate geographical regions (coast of Sussex, Firth of Forth [UK], Skjerstad fjord [Norway], Patagonian continental slope [Chile], Great Meteor Seamount [NE Atlantic]), along with examination of the available taxonomic literature regarding that species, identified errors in their determinations. An exhaustive and detailed morphological comparison was undertaken, revealing differences in the habitus and shape and ornamentation of appendages between specimens from different location. These differences are too great to represent intraspecific variability, and in fact are important discriminators for harpacticoid species.

The investigation was hindered by the inaccuracy and incompleteness of previous species descriptions, the inaccessibility of material for detailed comparison, and the absence of a 'molecular' option (due either to the rareness and/or uniqueness of material, or its method of fixation). Nevertheless, the morphological analysis recognized six morphospecies within Laophontodes typicus. As with moleculartaxonomic studies, a phylogenetic approach had to be discarded in favour of a diagnostic-typological one, including even apparent plesiomorphic character states for species discrimination. Based on this comparison, Laophontodes typicus was confirmed to be the correct designation for material collected by Ventham (2011) on the coast of Sussex (UK). However, a specimen described by T. Scott (1907) on the Scottish Firth of Forth, labelled as "Laophontodes typicus cotype" and kept in the collection of the Natural History Museum, London (UK) is now re-assigned as a new species, Laophontodes scottorum sp. nov. This material coincides with a redescription of L. typicus given by T. Scott (1907), which must therefore also be allocated to L. scottorum sp. nov. The redescription of L. typicus, based on material from the Norwegian coast and provided by Sars (1908) is redesignated Laophontodes norvegicus sp. nov., and additional Norwegian material also collected by G.O. Sars and determined as L. typicus by that author is redesignated Laophontodes sarsi sp. nov. Individuals reported from the Chilean Patagonian continental slope and identified as L. typicus by George $(1999,2005)$ are redesignated Laophontodes gertraudae sp. nov. Finally, material from the Great Meteor Seamount, previously identified as L. typicus by George \& Schminke (2002) is redesignated as Laophontodes monsmaris sp. nov.

The number and quality of the 22 morphological characters recognized in this study as well as their regionally unambiguous and consistent distribution debunks the theory of a high intraspecific variability within L. typicus. It is particularly important to note that many of the characters exhibiting variation between the examined specimens (e.g., reduction of setae, compression and flattening of the body, transformation of appendages etc.) are commonly used to discriminate between harpacticoid species. Thus, the present contribution not only describes five new species, but also confirms that a morphological analysis may be used to detect and redefine species complexes where molecular material is not available, even when the number of available characters is limited.

\section{Acknowledgments}

The author is indebted to Mrs Miranda Lowe (British Museum of Natural History, London, UK) and Mrs Åse Wilhelmsen (Natural History Museum, University of Oslo, Norway) for putting material of Laophontodes scottorum sp. nov. and L. sarsi sp. nov. at my disposal. Dr David Ventham (Brighton, UK) is kindly thanked for his hints that gave the impulse for undertaking this comparative study. Particular gratitude is owed to Dr Natalie Barnes (Lee-on-the-Solent, UK) for her quite helpful comments on the 
manuscript and the revision of the English text. Two anonymous reviewers provided very helpful and constructive comments on the manuscript. The author's participation on research cruise ANT XIII/4 (1996) was financially supported by the German Science Foundation DFG.

\section{References}

Arroyo N.L., George K.H., Benito J. \& Maldonado M. 2003. A new species of Ancorabolidae (Copepoda, Harpacticoida) from the northern coast of Spain: Laophontodes mourois sp. n. Hydrobiologia 498 (1-3): 169-176. https://doi.org/10.1023/A:1026274531719

Ax P. 1984. Das Phylogenetische System. Gustav Fischer Verlag, Stuttgart.

Chislenko L.L. 1967. Copepoda Harpacticoida of the Karelian coast of the White Sea. Proceedings of the White Sea Biological Station, Zoological Institute 7 (15): 48-196.

Chislenko L.L. 1977. Harpacticoids (Copepoda Harpacticoidea) from sponges of Franz Josef Land. Exploration of the fauna of the Seas. Biocoenoses of the shelf of Franz Josef Land and the fauna of adjacent waters 14 (22): 237-276.

Conroy-Dalton S. 2004. Systematics and phylogeny of the Ancorabolidae (Copepoda: Harpacticoida). V. Description of Lobopleura, new genus, with notes on Probosciphontodes Fiers. Journal of Crustacean Biology 24: 17-36. https://doi.org/10.1651/C-2439

Easton E.E., Thistle D. \& Spears T. 2010. Species boundaries in Zausodes-complex species (Copepoda: Harpacticoida: Harpacticidae) from the north-eastern Gulf of Mexico. Invertebrate Systematics 24: 258-270. https://doi.org/10.1071/IS09038

Fahrbach E. \& Gerdes D. (eds.) 1997. Die Expedition ANTARKTIS XIII/4-5 des Forschungsschiffes „Polarstern“ 1996. Berichte zur Polarforschung 239: 1-126.

George K.H. 1999. Gemeinschaftsanalytische Untersuchungen der Harpacticoidenfauna der Magellanregion, sowie erste similaritätsanalytische Vergleiche mit Assoziationen aus der Antarktis. Berichte zur Polarforschung 327: 1-187.

George K.H. 2005. Sublittoral and bathyal Harpacticoida (Crustacea: Copepoda) of the Magellan region. Composition, distribution and species diversity of selected major taxa. Scientia Marina 69 (2): 247-158. https://doi.org/10.3989/scimar.2005.69s2147

George K.H. 2006. Ancorabolinae Sars (Copepoda: Harpacticoida: Ancorabolidae) of the deep Atlantic Ocean. Ancorabolina chimaera gen. et sp. n. including remarks to ancorabolid phylogeny and to the evolution of the first natatorial leg in comparison with Laophontoidea T. Scott. Meiofaua Marina 15: $157-176$.

George K.H. 2017. Phylogeny of the taxon Paralaophontodes Lang (Copepoda, Harpacticoida, Laophontodinae), including species descriptions, chorological remarks, and a key to species. Zoosystematics and Evolution 93 (2): 211-241. https://doi.org/10.3897/zse.93.11314

George K.H. \& Gheerardyn H. 2015. Remarks on the genus Laophontodes T. Scott, 1894 (Copepoda, Harpacticoida, Ancorabolidae, Laophontodinae), including the (re-)description of four species. Zoologischer Anzeiger 259: 61-96. https://doi.org/10.1016/j.jcz.2015.02.009

George K.H. \& Schminke H.K. 2002. Harpacticoida (Crustacea, Copepoda) of the Great Meteor Seamount, with first conclusions as to the origin of the plateau fauna. Marine Biology 141: 887-895. https://doi.org/10.1007/s00227-002-0878-6

Gheerardyn H. \& Lee W. 2012. Calypsophontodes gen. nov. (Copepoda: Harpacticoida: Ancorabolidae), a new genus of Laophontodinae, including remarks on ancorabolid phylogeny. Journal of Crustacean Biology 32: 263-280. https://doi.org/10.1163/193724011X615613 
Huys R. \& Boxshall G.A. 1991. Copepod Evolution. The Ray Society Memoir 159, London.

Huys R., Gee J.M., Moore C.G. \& Hamond R. 1996. Marine and brackish water harpacticoid copepods. Part 1. Synopses of the British Fauna (New series) 51: 1-352.

Jakubisiak S. 1933. Les Harpacticoïdes marins recueillis pendant la croisière du navire-école polonais "Dar Pomorza" en hiver 1931-1932. Annals Musei Zoologici Polonici 10 (8): 87-92.

Jakubisiak S. 1936. Matériaux à la faune des harpacticoides de Roscoff. Fragmenta faunistica musei zoologici polonici 2 (28): 315-321.

Klie W. 1950. Harpacticoiden (Copepoden) aus dem Bereich von Helgoland und der Kieler Bucht (Fortsetzung). Kieler Meeresforschungen 7: 76-128.

Kornev P.N. \& Chertoprud E.S. 2008. Harpacticoid copepods from the White Sea: Morphology, Systematics, Ecology. KMK Scientific Press, Moscow.

Lang K. 1934. Marine Harpacticoida von der Campbell-Insel und einigen anderen südlichen Inseln. Lunds Universitets Arsskrift N.F. Avd. 2 (30) (14): 1-56.

Lang K. 1948. Monographie der Harpacticiden. Otto Koeltz Science Publishers, Koenigstein.

Lang K. 1965. Copepoda Harpacticoida from the Californian pacific coast. Kungliga Svenska Vetenskapsakademiens Handlingar 10: 1-566.

Roe K.M. 1958. The littoral harpacticids of the Dalkey (co. Dublin) area with descriptions of six new species. Proceedings of the Royal Irish Academy 59: 221-255.

Sars G.O. 1908. An account of the Crustacea of Norway with short descriptions and figures of all the species. 5. Copepoda Harpacticoida. Parts XXIII and XXIV: Laophontidae (cont.): 257-276. The Bergen Museum, Bergen.

Schizas N.V. \& Shirley T.C. 1994. Two new species of Laophontodes (Copepoda, Harpacticoida, Ancorabolidae) from McMurdo Sound, Antarctica. Zoologica Scripta 23 (3): 205-216.

https://doi.org/10.1111/j.1463-6409.1994.tb00385.x

Schminke H.K. 1976. The ubiquitous telson and the deceptive furca. Crustaceana 30: 292-299. https://doi.org/10.1163/156854076X00657

Scott T. 1894. Additions to the fauna of the Firth of Forth. Part III. Annual Report of the Fishery Board for Scotland 12 (3): 231-271.

Scott T. 1903. On some new and rare Crustacea collected at various times in connection with the investigations of the fishery boards for Scotland. Annual Report of the Fishery Board for Scotland 21 (3): 109-135.

Scott T. 1907. Some additional notes on Copepoda from Scottish seas. Annual Report of the Fishery Board for Scotland 25 (3): 209-220.

Ventham D. 2011. Harpacticoid copepods from the Sussex coast (eastern English Channel): records 1992-1997. The Booth Museum of Natural History, Brighton.

Wells J.B.J. 2007. An annotated checklist and keys to the species of Copepoda Harpacticoida (Crustacea). Zootaxa 1568: 1-872.

Willen E. 2000. Phylogeny of the Thalestridimorpha Lang, 1944 (Crustacea, Copepoda). Cuvillier Verlag, Göttingen. 
Manuscript received: 21 December 2017

Manuscript accepted: 14 February 2018

Published on: 29 May 2018

Topic editor: Rudy Jocqué

Desk editor: Pepe Fernández

Printed versions of all papers are also deposited in the libraries of the institutes that are members of the EJT consortium: Muséum national d'Histoire naturelle, Paris, France; Botanic Garden Meise, Belgium; Royal Museum for Central Africa, Tervuren, Belgium; Natural History Museum, London, United Kingdom; Royal Belgian Institute of Natural Sciences, Brussels, Belgium; Natural History Museum of Denmark, Copenhagen, Denmark; Naturalis Biodiversity Center, Leiden, the Netherlands; Museo Nacional de Ciencias Naturales-CSIC, Madrid, Spain; Real Jardín Botánico de Madrid CSIC, Spain; Zoological Research Museum Alexander Koenig, Bonn, Germany. 